CONSISTENT ESTIMATION OF CONDITIONAL CONSERVATISM

\title{
Manuel Cano-Rodríguez
}

Universidad de Jáen - Department of Financial Economics and Accounting mcano@ujaen.es

\section{Manuel Núñez-Nickel}

Universidad Carlos III de Madrid - Department of Business Administration mnunez@emp.uc3m.es

March, 2011.

The authors are indebted to Beatriz Moreno, Bing Guo, Juan Manuel García-Lara and William Rees for their useful comments. This research is funded by the SEJ2007-65782-C02-02ECON and the ECO201022105-C03-03 (subprogram ECON) research projects of the Spanish Ministry of Science and Education, and the INFOINNOVA research project of the Community of Madrid. 


\title{
CONSISTENT ESTIMATION OF CONDITIONAL CONSERVATISM
}

\begin{abstract}
In this paper, we demonstrate analytically that Basu model estimates are affected by two biases, except if very restrictive conditions are met: an aggregation bias produced by the absence of the book-to-market ratio in Basu model, and (2) an aggregation problem produced by the use of total market returns instead of separating the good news and bad news of the period. To solve this problem, we propose an alternative econometric model that is robust to both biases. The empirical results obtained using archival data demonstrate the advantages of robustness of our alternative econometric model compared to Basu model: it controls the omitted variable bias, is robust to the aggregation effect, its estimates are less influenced by the extreme values of market returns, and it presents a higher explanatory power.
\end{abstract}

Keywords: accounting conservatism; conditional conservatism; unconditional conservatism; Basu model; aggregation effect; omitted variable bias.

\section{INTRODUCTION.}

In this paper, we develop a theoretical framework that describes the relation between the market returns and accounting net income. Using this framework as a starting point, we evaluate the capability of Basu model to accurately estimate the recognition parameters of good and bad news on accounting, demonstrating that, except under very restrictive conditions, Basu model is affected by two biases. The first bias is produced by the absence of the book-to-market ratio in Basu model. According to our theoretical framework, accounting net income is not only influenced by the contermporaneous market returns, but by the book-to-market ratio at the beginning of the period too; given that the the book-to-market ratio is correlated with market returns, the absence of this variable in Basu model produces the omitted variables bias. The second bias is produced by the aggregation effect described by Givoly et al. (2007): Basu model uses the total market return of the period and, therefore, it does not separate the good news of the period from the bad news of the period, but obtains the relationship between net income and the aggregation of all the good news and the bad news of the period. Givoly et al. (2007) demonstrated with simulated data that this aggregation effect produced a downward bias in the differential timeliness of bad news compared to good news. In 
this paper, we extend the work of Givoly et al. (2007) by providing a theoretical explanation for the aggregation effect, and showing that this bias can be both a downwards and an upwards bias, depending on the influence of bad news on the total returns of the period.

In addition to the analytical demonstration of the biases of Basu model, we propose an econometric model, based on Basu's definition of conservatism and our own theoretical framework, which is robust to the two biases. Using archival data, we compare the performance of the Basu model and our alternative model, obtaining that the alternative model presents several advantages over the traditional Basu model: its estimates are more consistent with the theoretical framework; they are robust to the aggregation bias and less influenced by the observations with extreme market returns; and, finally, the explanatory power of the alternative model is higher than that of Basu model. Consequently, in this paper we provide an econometric model that, starting from Basu's definition of conservatism, produces more reliable estimates of the relations between accounting earnings and both good and bad news.

The remainder of the paper is structured as follows: first, we remember Basu model and some of its problems; next, we develop the theoretical framework for the relation between accounting earnings and the market returns; then, in Section 4, we evaluate the capability of Basu model to produce inconsistent estimations of the return-earnings relation described in our theoretical model; in Section 5, we develop the alternative econometric model; in Section 6, we compare the capability of Basu and the alternative model to produce consistent estimates of the relation between earnings and returns, applying both models to simulated data; in Section 7, we compare the behaviour of the two models with actual data; Section 8 concludes.

\section{DESCRIPTION OF BASU MODEL AND ITS PROBLEMS.}

Basu model (Basu 1997) relies on the assumption that accounting conservatism leads to a faster recognition of bad news than good news. Consequently, the contemporaneous relation between negative market returns (as a proxy of bad news) and accounting earnings is expected to be higher than the contemporaneous relation between positive market returns (as a proxy of good news) and accounting earnings. According to this, Basu model can be expressed as shown in equation (1): 
$\frac{A N I_{t}}{M_{t-1}}=\alpha_{0}+\alpha_{1} \cdot d_{t}+\beta_{0} \cdot R_{t}+\beta_{1} \cdot d_{t} \cdot R_{t}+\varepsilon_{t}$

Where $A N I_{t}$ is the accounting net income obtained in period $t ; M_{t-1}$ is the market value of equity at the beginning of the period $t$; $R_{t}$ is the market rate of return for the period $t$; $d_{t}$ is a dummy variable that equals one if $R_{t}$ is negative and zero otherwise; and $\varepsilon_{t}$ is the error term. Parameter $\beta_{0}$ captures the relation between earnings and positive market returns, while parameter $\beta_{1}$ captures the difference in the reaction of earnings to negative returns compared to positive returns. Parameters $\alpha_{0}$ and $\alpha_{1}$ are the intercepts of the model.

Consistently with the hypothesized differential timeliness, Basu obtains that the reaction of earnings to negative market returns is greater than the reaction to positive market returns, thereby producing a positive value for coefficient $\beta_{1}$. From this seminal work, Basu model has become one of the prevalent models for testing the existence of accounting conservatism (Ryan 2006; Ball et al. 2009; Khan and Watts 2009). However, and despite its popularity, previous literature has pointed that Basu model presents various weaknesses that put into question the validity of its results (Dietrich et al. 2007; Givoly et al. 2007; Patatoukas and Thomas 2009). In this paper, we contribute to this research stream by demonstrating analytically that Basu model produces inconsistent estimations of the relation between accounting net income and market returns, since their estimates are affected by two biases: the first bias is an omitted variable bias. In our theoretical model, we show that the portion of accounting net income which is not related to the contemporaneous market returns is related to the book-to-market ratio. Consequently, as the book-to-market ratio is also related to market returns, the absence of this variable in Basu model biases the estimates of the relation between accounting earnings and market returns. The second bias is produced by the aggregation effect: Basu model does not estimate the influence of each economic individual gain or loss on accounting net income, but it estimates the relationship between net income and the aggregation of all the economic gains and losses of the period, that is, the total market return of the period. This problem has been initially detected by Givoly et al. (2007), who, using simulated data, obtain that the coefficient that measures the earnings differential timeliness $\left(\beta_{1}\right)$ drops as the number of economic events in a period increase. Besides, this fall in the value of the coefficient is more evident when the positive and negative shocks are identically distributed, making more 
likely the compensation between the economic gains and losses of the same period. They conclude that the aggregation problem produces a dissipation of the evidence of conservatism when the different economic events of a period are likely to offset each other. In this paper, we show analytically that the bias produced in the earnings differential timeliness measure can be positive or negative (that is, it can dissipate the evidence of conservatism or it can exaggerate it), depending on the relation between the bad news and the good news of the period.

Finally, another minor inconvenient of Basu model is its difficulty to produce firmspecific measures of accounting conservatism. Although, in theory, these firm-specific measures could be obtained using firm-specific time-series estimations, in the practice this method is likely to produce noisy estimates of the coefficients because few companies have sufficient number of years with negative returns for the time-series estimation of the model (Zhang 2008) ${ }^{1}$.

These drawbacks cast doubt on the reliability of Basu model to measure conservatism. Given the popularity of this model, this lack of reliability would be applicable to many (if not most) of the papers that have based their conclusions on the results of this model.

\section{A THEORETICAL FRAMEWORK OF THE RELATION BETWEEN ACCOUNTING EARNINGS AND MARKET RETURN}

In this section, we derive a theoretical firm-specific model that relates the variations in the market value of equity of the firm occurred during a period with the accounting earnings recorded for that period. First, we expose how good and bad news are timely incorporated on the market value of equity; then, we will describe the formation of the accounting earnings of the period and its relation with the variations of the market value.

\subsection{The influence of good and bad news on market return}

Under the assumption that capital markets are efficient, we can expect market prices to reflect all the publicly available information timely (Ball et al. 2009). Consequently, the market value of equity will be equal to the present value of the expected future cash flows of the firm. Additionally, any change in that present value produced by an unexpected event, will be instantaneously incorporated in the market value of equity.

\footnotetext{
${ }^{1}$ In its extreme, coefficient $\beta_{1}\left(\beta_{0}\right)$ could not be estimated for those companies with no negative (positive) return in their time-series during the test period.
} 
The market value of equity at any given moment $t$ can be obtained by the following expression:

$M_{t}=M_{t-1}+\Delta M_{t}$

Where $M_{t}$ is a random variable that symbolizes the market value of equity at the end of period $t$, and $M_{t-1}$ is the market value of equity at the beginning of period $t ; \Delta M_{t}$ is the sum of all the variations (increases and decreases) in the market value of equity, occurred between $t-1$ and $t$. According to this definition, $\Delta M_{t}$ can be computed as:

$$
\Delta M_{t}=\sum_{j=1}^{n_{t}} \Delta m_{j, t}
$$

Where $n_{t}$ is the number of economic events that alter the market value of equity between $t-1$ and $t$, and $\Delta m_{j, t}$ is the variation in the market value produced the event $j$. We assume $\Delta m_{j, t}$ to be stationary and symmetric random variables. In other words, $n_{t}$ can be interpreted as the number of variations in the stock price of a firm during a given period (a year, a trimester, a month, a day...), and $\Delta m_{j, t}$ as the value of each individual variation.

Let us now consider that some of the events of the period are "good news" (that is, they produce an increase in $M$ ) and the remainder events are "bad news" (produce a decrease in $M$ ). We denote the positive variations in the market value of equity produced by good news as $\Delta m_{j, t}^{+}$. Thus, $\Delta m^{+}{ }_{j, t}$ will be equal to $\Delta m_{j, t}$ if $\Delta m_{j, t}$ is positive, and zero otherwise. Analogously, $\Delta m_{j, t}^{-}$represents the negative variations in the value of $M$, consequence of the occurrence of bad news. Hence, $\Delta m_{j, t}^{-}$will be equal to $\Delta m_{j, t}$ if $\Delta m_{j, t}$ is negative, and zero otherwise. By introducing $\Delta m_{j, t}^{+}$and $\Delta m_{j, t}^{-}$in equation (3), we obtain:

$$
\Delta M_{t}=\sum_{j=1}^{n_{t}} \Delta m_{j, t}^{+}+\sum_{j=1}^{n_{t}} \Delta m_{j, t}^{-}
$$

For simplicity, we denote $\sum_{j=1}^{n_{t}} \Delta m_{j, t}^{+}$by $\Delta M^{+}{ }_{t}$ and $\sum_{j=1}^{n_{t}} \Delta m_{j, t}^{-}$by $\Delta M_{t} . \Delta M_{t}$ would therefore be:

$$
\Delta M_{t}=\Delta M_{t}^{+}+\Delta M_{t}^{-}
$$


In simply words, expression (5) is indicating that the total variation in the stock price during a period can be calculated as the sum of all the positive and all the negative variations produced between the beginning and the end of that period. For example, the net variation in the stock price during a year can be calculated as the sum of all the positive and negative monthly (weekly, daily...) variations occurred in that year. By dividing expression (5) by the market value of equity at the beginning of the period, we obtain the same relation for market returns:

$\frac{\Delta M_{t}}{M_{t-1}}=\frac{\Delta M_{t}^{+}}{M_{t-1}}+\frac{\Delta M_{t}^{-}}{M_{t-1}}=R_{t}^{+}+R_{t}^{-}$

\subsection{The influence of good and bad news on accounting net income}

In this theoretical framework, we assume that the accounting net income does not reflect the economic gains and losses as timely as the market value. The reason is that the accounting gains or losses are not recorded unless they meet the accounting recognition criteria, based on requirements of verifiability, objectivity and conservatism. Some economic gains/losses can meet these accounting requirements in the same period that they are generated, and, consequently, they will affect to the market and the book value of equity in that same period (for example, an unexpected increase in sales in the current period that is not expected to affect the sales of the future periods). Some other economic gains or losses, however, can fulfil those requirements only partially. In this case, the market value of equity will be affected by the total amount of the gain/loss, but the accounting net income will incorporate just the portion of that economic gain/loss that meet the recognition criteria. The remainder of that economic gain/loss will be recognized in future periods, as it fulfils the accounting requirements (an example could be an unexpected increase in sales in the current period that is expected to affect also to the sales of the future periods. In this case, the present value of all the expected variations in the cash flows will be incorporated into the stock prices, but only the increase in the sales of the current period will be recognized as net income in this period. The rest of the value, created by the expectations of future sale increases, will be recorded in future periods, as such increases are realized).

Finally, we can also consider other economic gains/losses that, despite they can affect the market value in the current period, do not meet the requirements to be included in 
the accounting income of this period. These economic gains/losses, though, will be recorded as gains/losses in the future, when they meet the required conditions (for example, the potential capital gains in fixed assets that are recorded at their purchase cost will be recognized in the market value of equity, but those potential capital gains will not be recognized in accounting until the asset is sold).

Given that under accounting conservatism losses are recorded more timely than gains (Basu, 1997), we incorporate this possibility by differentiating between economic gains and losses. Accounting net income is hence expressed as follows:

$$
A N I_{t}=\alpha_{t}+\sum_{j=1}^{n_{t}} \beta_{j, t}^{+} \cdot \Delta m_{j, t}^{+}+\sum_{j=1}^{n_{t}} \beta_{j, t}^{-} \cdot \Delta m_{j, t}^{-}
$$

Where $A N I_{t}$ represents the accounting net income of period $t . \beta_{j, t}^{+}$and $\beta_{j, t}^{-}$indicate the portion of the economic gain $\Delta m_{j, t}^{+}$or the economic loss $\Delta m_{j, t}^{-}$, respectively, that meet the requirements to be registered as an accounting gain or loss in the period $t$. We assume that $\beta_{j, t}^{+}$and $\beta_{j, t}^{-}$are stationary and symmetric random variables with means $\overline{\beta^{+}}$and $\overline{\beta^{-}}$, respectively. We also assume that they are not correlated over time and they are independent from the amount of the economic gain or loss $\left(\Delta m_{j, t}^{+}\right.$or $\left.\Delta m_{j, t}^{-}\right)$. Finally, $\alpha_{t}$ is the portion of the accounting net income that is independent of the economic gains or losses of the same period $t$. We will discuss later the composition of this $\alpha_{t}$.

According to the former theoretical framework, the value of $\beta_{j, t}^{+}$and $\beta_{j, t}^{-}$ranges from 0 to 1 , both inclusive. Thus, if the effect of the unexpected event meets the accounting requirements to be fully incorporated in the accounting net income of the current period, the value of the beta parameter will be equal to 1 , and the variation of the market and the book values of equity produced by the economic event will coincide. When only a portion of the variation of the market value of equity meets the accounting requirements to be recorded in the current year, the beta coefficient indicate the proportion of the total change in the market value that is recorded, being this proportion between zero and one. In this case, the variation that the economic event has produced in the market value of equity will be higher than the variation produced in the book value of equity. Finally, if the economic effect of the unexpected event does not meet the accounting criteria to be recognized as a gain or a loss in the current period, the value of the parameter beta will 
be equal to zero. In this case, we obtain that the economic event produces a variation in the stock market of equity but no variation in the book value of equity.

We focus now in the intercept of equation (7). As it has been indicated above, this parameter captures the accounting gains and losses registered on period $t$ that do not proceed from the variations of the market value of equity occurred in the same period. These gains and losses can, then, proceed from three different sources:

a) First, they can be gains and losses that affected the market value of equity in previous periods, but have not met the requirements to be recognized as accounting gains or losses until the current period. Therefore, these gains and losses are already incorporated in the market value of equity at the beginning of the period $\left(M_{t-1}\right)$, but not in the book value of equity at the beginning of the period $\left(B_{t-1}\right)$. Consequently, the accounting recognition of these gains and losses contribute to reduce the difference between the market and the book values of equity.

b) Second, they can be accounting gains and losses that are unrelated to all the current and past market value variations. These gains and losses would be, then, the accounting recognition of potential future economic gains or losses that have not been incorporated in stock prices. However, under the hypothesis of market efficiency, the stock prices will incorporate all the expected future gains and losses. Consequently, these accounting gains or losses will be overstatements of the potential future gains and losses. Under accounting conservatism, this overstatement is not possible for gains ${ }^{2}$, but it is possible for losses. This accounting overstatement of potential losses has been named in previous literature as unconditional conservatism. Some examples of this practices would be the overestimation of accounting depreciation, of bad debts or the use of the LIFO method for stock valuation (Qiang 2007). Unconditional conservatism, then, will imply a reduction of the book value of equity $\left(B_{t}\right)$ with no variation in the market value of equity $\left(M_{t}\right)$.

c) Finally, unconditional conservatism practices produce a downward bias in book value of equity compared to market value of equity. This bias will tend to disappear through time, when the overstated losses are realized. For example, an overstated depreciation of a fixed asset will produce an understatement of book

\footnotetext{
${ }^{2}$ If we exclude the possibility of earnings management.
} 
value of equity compared to market book of equity, but this understatement will disappear when the fixed asset is sold and the capital gains are recognized in the accounting net income. The consequence of this reversion of unconditional conservatism will be a reduction of the difference between the market and book values of equity.

In summary, the intercept of the model for a given period $t$ is formed by two components: (1) the amount of unconditional conservatism recorded in period $t$; and (2) the reduction of the difference between the market and the book values of equity at the beginning of the period. This reduction can be achieved by reverting the unconditional conservatism recorded in previous periods or by recognizing in the accounting net income the past market value variations that meet the accounting criteria in the current period $t$. Parameter $\alpha_{t}$ can hence be computed as:

$\alpha_{t}=U C_{t}+\delta_{t} \cdot\left(M_{t-1}-B_{t-1}\right)$

Where $\delta_{t}$ indicates the portion of the difference between $M_{t-1}$ and $B_{t-1}$ that is incorporated in $A N I_{t}$ as a consequence of the recognition of past variations of market value and/or the reversion of past unconditional conservatism; and $U C_{t}$ is the new unconditional conservatism recorded between $t-1$ and $t$.

Finally, to make our model more comparable to Basu model, we divide the two members of the equation by the market value at the beginning of the period. The result is presented next:

$$
\frac{A N I_{t}}{M_{t-1}}=\frac{U C_{t}}{M_{t-1}}+\delta_{t} \cdot \frac{\left(M_{t-1}-B_{t-1}\right)}{M_{t-1}}+\sum_{j=1}^{n_{t}} \beta_{j, t}^{+} \cdot \frac{\Delta m_{j, t}^{+}}{M_{t-1}}+\sum_{j=1}^{n_{t}} \beta_{j, t}^{-} \cdot \frac{\Delta m_{j, t}^{-}}{M_{t-1}}
$$

Since $\beta_{j}^{+}$and $\beta_{j}^{-}$are assumed symmetric random variables, we can express them as follows:

$$
\begin{aligned}
& \beta_{j}^{+}=\overline{\beta^{+}}+v_{j}^{+} \\
& \beta_{j}^{-}=\overline{\beta^{-}}+v_{j}^{-}
\end{aligned}
$$

Where $v_{j}^{+}$and $v_{j}^{-}$are the deviations from the expectation of $\beta_{j}^{+}$and $\beta_{j}^{-}$, respectively. The mean of these two variables is zero and they are independent from the other random variables, particularly from $\Delta m_{j}^{+}$and $\Delta m_{j}^{-}$. Substituting (10) in (9), we obtain: 


$$
\begin{aligned}
\frac{A N I_{t}}{M_{t-1}} & =\frac{U C_{t}}{M_{t-1}}+\delta_{t} \cdot \frac{\left(M_{t-1}-B_{t-1}\right)}{M_{t-1}}+\sum_{j=1}^{n_{t}}\left(\overline{\beta^{+}}+v_{j, t}^{+}\right) \cdot \frac{\Delta m_{j, t}^{+}}{M_{t-1}}+\sum_{j=1}^{n_{t}}\left(\overline{\beta^{-}}+v_{j, t}^{-}\right) \cdot \frac{\Delta m_{j, t}^{-}}{M_{t-1}}= \\
& =\frac{U C_{t}}{M_{t-1}}+\delta_{t} \cdot \frac{\left(M_{t-1}-B_{t-1}\right)}{M_{t-1}}+\sum_{j=1}^{n_{t}} \overline{\beta^{+}} \cdot \frac{\Delta m_{j, t}^{+}}{M_{t-1}}+\sum_{j=1}^{n_{t}} \overline{\beta^{-}} \cdot \frac{\Delta m_{j, t}^{-}}{M_{t-1}}+\sum_{j=1}^{n_{t}} v_{j, t}^{+} \cdot \frac{\Delta m_{j, t}^{+}}{M_{t-1}}+v_{j, t}^{-} \cdot \frac{\Delta m_{j, t}^{-}}{M_{t-1}}
\end{aligned}
$$

Finally, we define $\xi_{t}=\sum_{j=1}^{n_{t}} v_{j, t}^{+} \cdot \frac{\Delta m_{j, t}^{+}}{M_{t-1}}+v_{j, t}^{-} \cdot \frac{\Delta m_{j, t}^{-}}{M_{t-1}}$. As the means of $v_{j}^{+}$and $v_{j}^{-}$are zero and these variables are independent from any other random variable, we can conclude that $\xi_{t}$ is a random variable with null mean and independent of $R_{t}^{+}$and $R_{t}^{-}$. The final version of the model then remains:

$$
\begin{aligned}
\frac{A N I_{t}}{M_{t-1}} & =\frac{U C_{t}}{M_{t-1}}+\delta_{t} \cdot \frac{\left(M_{t-1}-B_{t-1}\right)}{M_{t-1}}+\sum_{j=1}^{n_{t}} \overline{\beta^{+}} \cdot \frac{\Delta m_{j, t}^{+}}{M_{t-1}}+\sum_{j=1}^{n_{t}} \overline{\beta^{-}} \cdot \frac{\Delta m_{j, t}^{-}}{M_{t-1}}+\xi_{t}= \\
& =\frac{U C_{t}}{M_{t-1}}+\delta_{t} \cdot \frac{\left(M_{t-1}-B_{t-1}\right)}{M_{t-1}}+\overline{\beta^{+}} \cdot R_{t}^{+}+\overline{\beta^{-}} \cdot R_{t}^{-}+\xi_{t}
\end{aligned}
$$

\section{AN EVALUATION OF BASU MODEL ESTIMATES}

In this section, we evaluate if Basu's model correctly captures the relation between accounting net income and market returns described in the theoretical framework, demonstrating that, under normal conditions, the estimated parameters are inconsistent estimations of the relationships between accounting net income and positive and negative variations in market value.

In order to facilitate this evaluation, we add and subtract $\beta^{+} \cdot R_{t}^{-}$in equation (12) obtaining that:

$$
\begin{aligned}
\frac{A N I_{t}}{M_{t-1}} & =\frac{U C_{t}}{M_{t-1}}+\delta_{t} \cdot \frac{\left(M_{t-1}-B_{t-1}\right)}{M_{t-1}}+\overline{\beta^{+}} \cdot R_{t}^{+}+\overline{\beta^{-}} \cdot R_{t}^{-}+\xi_{t}+\overline{\beta^{+}} \cdot R_{t}^{-}-\overline{\beta^{+}} \cdot R_{t}^{-}= \\
& =\frac{U C_{t}}{M_{t-1}}+\delta_{t} \cdot \frac{\left(M_{t-1}-B_{t-1}\right)}{M_{t-1}}+\overline{\beta^{+}} \cdot\left(R_{t}^{+}+R_{t}^{-}\right)+\left(\overline{\beta^{-}}-\overline{\beta^{+}}\right) \cdot R_{t}^{-}+\xi_{t}= \\
& =\frac{U C_{t}}{M_{t-1}}+\delta_{t} \cdot \frac{\left(M_{t-1}-B_{t-1}\right)}{M_{t-1}}+\overline{\beta^{+}} \cdot R_{t}+\left(\overline{\beta^{-}}-\overline{\beta^{+}}\right) \cdot R_{t}^{-}+\xi_{t}
\end{aligned}
$$

According to the theoretical framework, the average contemporaneous relationship between earnings and good news is captured by $\overline{\beta^{+}}$; the average contemporaneous relationship between earnings and bad news is $\overline{\beta^{-}}$; and the difference between $\overline{\beta_{+}^{-}}$and $\overline{\beta_{+}^{+}}$indicates the existence of a difference in the timely recognition of gains and losses. 
Next we evaluate if Basu model rightly captures the contemporaneous relation between market value variations and accounting earnings. For doing so, Basu's coefficient $\beta_{0}$ should be an unbiased estimator of $\overline{\beta^{+}}$, that is, the contemporaneous relationship between accounting net income and the effect of good news on market value; similarly, the coefficient $\beta_{1}$ should be an unbiased estimator of $\overline{\beta^{-}}-\overline{\beta^{+}}$, that is, the difference in the timely recognition of gains and losses. In the following subsection, we analyze if the Ordinary Least Squares (OLS) estimations of Basu model coefficients are unbiased estimators of those parameters of our theoretical model.

\subsection{Basu's estimates of the influence of good news on accounting net income.}

In this section, we present the demonstration of our first proposition.

Proposition 1: In presence of accounting conservatism, Basu model produces a biased estimation of the influence of good news on accounting earnings, except under very restrictive conditions.

Let $\hat{\beta}_{0}$ denote the Ordinary Least Squares (OLS) estimation of $\beta_{0}$ from equation (1). The value of this $\hat{\beta}_{0}$ converges in probability in:

$$
p \lim \hat{\beta}_{0}=\frac{\operatorname{Cov}\left(\frac{A N I_{t}}{M_{t-1}}, R_{t} \mid R_{t}>0\right)}{\operatorname{Var}\left(R_{t} \mid R_{t}>0\right)}
$$

In Appendix A, we demonstrate that, under the assumptions of the former theoretical framework, the value of expression (14) is the following:

$$
p \lim \hat{\beta}_{0}=\overline{\beta^{+}}-\underbrace{\frac{\delta \cdot \operatorname{Cov}\left(\frac{B_{t-1}}{M_{t-1}}, R_{t} \mid R_{t} \geq 0\right)}{\operatorname{Var}\left(R_{t} \mid R_{t} \geq 0\right)}}_{\text {Omitted variable bias }}+\underbrace{\left(\overline{\beta^{-}}-\overline{\beta^{+}}\right) \cdot \frac{\operatorname{Cov}\left(R_{t}^{-}, R_{t} \mid R_{t} \geq 0\right)}{\operatorname{Var}\left(R_{t} \mid R_{t} \geq 0\right)}}_{\text {Aggregation bias }}
$$


Indicating that $\hat{\beta}_{0}$ is a biased estimator of $\overline{\beta^{+}}$except if the sum of the second and the third addends (named omitted variable bias and aggregation bias) is exactly equal to zero. This will happen if the two biases are equal to zero or, if they differ from zero, if they are of the same magnitude, but with opposite sign. Given that the two biases arise from different reasons (the omission of the book-to-market ratio in the Basu model for the first, and the aggregation effect for the second), we consider that the possibility that the two biases, being different from zero, offset each other is remote. Consequently, we focus on the possibility that the two biases are equal to zero.

For the omitted variable bias to be equal to zero, the book-to-market ratio, measured at the beginning of the period, should be uncorrelated to market returns when these returns are positive. However, this lack of relation seems unlikely, because previous research has widely documented that the book-to-market exhibit a high power in the prediction of the cross-sectional distribution of returns, showing a positive relation between these two measures (see, for instance, Fama and French 1992; Pontiff and Schall 1998; Lewellen 1999). Consequently, the existence of a positive relation between the book-tomarket ratio and market returns would produce a downwards bias in the estimation of the relation between accounting net income and positive market returns.

Regarding the aggregation bias, it will be null if one of the two following conditions is met:

Condition $1: \overline{\beta^{-}}=\overline{\beta^{+}}$. In this case, there is no differentiation in the timely recognition of good and bad news and, therefore, there is no accounting conservatism.

Condition 2: $\operatorname{Cov}\left(R_{t}^{-}, R_{t} \mid R_{t}>0\right)=0$. In other words, if the negative variations in the market value during the period have no influence at all on the return of that period. We consider these two conditions too restrictive. On the one hand, conservatism is a common principle in accounting, what implies that it is reasonable to expect that the financial statements of the companies will be conservative, and not neutral nor aggressive. Consequently, we consider that condition 1 is not a realistic condition, being more appropriate to expect that $\overline{\beta^{-}}>\overline{\beta^{+}}$.

Condition 2, on the other hand, implies that the market return is independent from the bad news of the period. In appendix A, we show that this will happen only if the correlation between good and bad news is exactly equal to minus the deviation of bad news divided by the deviation of good news. To our knowledge, there is no theoretical 
reason to expect that the correlation between good and bad news will be equal to the proportion of standard deviations.

In summary, the requirements for $\hat{\beta}_{0}$ to be an unbiased estimator of the relation between accounting net income and good news seem too restrictive to expect being widely observed in actual data. Therefore, we conclude that $\hat{\beta}_{0}$ is likely to be a biased estimator of $\overline{\beta^{+}}$parameter. However, the sign and size of that bias will depend on various factors, such as the relation between market returns and the book-to-market ratio or the correlation between good news and bad news.

\subsection{Basu's estimates of the differential influence of bad news on accounting net income.}

Our second proposition is the following:

Proposition 2: In presence of accounting conservatism, Basu model produces a biased estimation of the influence of bad news on accounting earnings, except under very restrictive conditions.

Let now $\hat{\beta}_{1}$ represent the Ordinary Least Squares (OLS) estimation of the parameter $\beta_{1}$ from equation(1). The value of $\hat{\beta}_{1}$ converges in probability in:

$p \lim \hat{\beta}_{1}=\frac{\operatorname{Cov}\left(\frac{A N I_{t}}{M_{t-1}}, R_{t} \mid R_{t}<0\right)}{\operatorname{Var}\left(R_{t} \mid R_{t}<0\right)}-\frac{\operatorname{Cov}\left(\frac{A N I_{t}}{M_{t}}, R_{t} \mid R_{t}>0\right)}{\operatorname{Var}\left(R_{t} \mid R_{t}>0\right)}$

Under the assumptions of the theoretical framework, the former expression is equal to (see Appendix B for demonstration):

$$
p \lim \hat{\beta}_{1}=\left(\overline{\beta^{+}}-\overline{\beta^{-}}\right) \cdot \underbrace{\left[\frac{\operatorname{Cov}\left(R_{t}^{-}, R_{t} \mid R_{t}<0\right)}{\operatorname{Var}\left(R_{t} \mid R_{t}<0\right)}-\frac{\operatorname{Cov}\left(R_{t}^{-}, R_{t} \mid R_{t} \geq 0\right)}{\operatorname{Var}\left(R_{t} \mid R_{t} \geq 0\right)}\right]}_{\text {Aggregation bias }}-\delta \cdot \underbrace{\left[\frac{\operatorname{Cov}\left(\frac{B_{t-1}}{M_{t-1}}, R_{t} \mid R_{t}<0\right)}{\operatorname{Var}\left(R_{t} \mid R_{t}<0\right)}-\frac{\operatorname{Cov}\left(\frac{B_{t-1}}{M_{t-1}}, R_{t} \mid R_{t} \geq 0\right)}{\operatorname{Var}\left(R_{t} \mid R_{t} \geq 0\right)}\right]}_{\text {Omitted variable bias }}
$$

$\hat{\beta}_{1}$ would be an unbiased estimator of $\left(\overline{\beta^{-}}-\overline{\beta^{+}}\right)$if the two biases cancel each other.

However, the different nature of the two biases and their different effects on the value of 
$\hat{\beta}_{1}$ (the aggregation bias has a multiplicative effect, while the omitted variable bias has an additive effect) make unlikely such cancellation.

Another possibility is that the value of the omitted variable bias is equal to zero and the value of the aggregation bias is equal to one.

The omitted variable bias would be equal to zero if the relation between the ratio bookto-market and negative returns is exactly the same as the relation between the same ratio and positive returns. If those relations are different, they would introduce a bias in the estimation of $\hat{\beta}_{1}$. The sign and magnitude of this bias, however, would depend on the difference between the two former relations.

The aggregation bias is composed by the difference of the relation between bad news and negative returns, minus the relation between good news and positive returns. This bias will have no effect on the validity of $\hat{\beta}_{1}$ if the value of this difference is exactly equal to one. However, there is no theoretical reason for expecting such a value. Consequently, the aggregation bias can lead Basu model to underestimate conditional conservatism (if the value of the aggregation bias is lower than one) or to overestimate conditional conservatism (in case the value of the aggregation bias is higher than one). Again, we consider the conditions for being an unbiased estimator of conditional conservatism too restrictive. In conclusion, Basu model is very likely to estimate conditional conservatism with bias. The sign and magnitude of such bias, however, is an empirical issue.

\section{AN ALTERNATIVE ECONOMETRIC MODEL}

As we have demonstrated in section 4, except under very restrictive conditions, Basu model produces biased estimations of the relation between market returns and accounting net income because of the aggregation effect. In this section, we propose an alternative empirical model that follows the theoretical framework described in section 3. This econometric model is the following:

$$
A N I_{t}=a_{0}+a_{1} \cdot\left(1-B T M_{t-1}\right)+b_{0} \cdot R_{t}^{+}+b_{1} \cdot R_{t}^{-}+\varepsilon_{t}
$$

Where $a_{0}$ is the intercept of the model and captures the level of unconditional conservatism of the company $\left(U C_{t}\right)$; coefficient $a_{1}$ captures those accounting gains and losses that are related to the relation between the market and the book values of equity 
at the beginning of the period $\left(\delta_{t}\right)$; and coefficients $b_{0}$ and $b_{1}$ represent, respectively, the influence of the good news and the news of the period on the accounting net income of the same period $\left(\overline{\beta^{+}}\right.$and $\left.\overline{\beta^{-}}\right)$.

Although this alternative model is based upon the same concept of conservatism than Basu model, it controls the two biases detected for Basu model: the omitted variable bias is corrected with the introduction of the book-to-market ratio, and the aggregation bias is corrected by differentiating the good news from the bad news of the same period.

\section{EMPIRICAL COMPARISON OF BASU MODEL AND THE ALTERNATIVE MODEL}

In section 4 we have demonstrated that, under our theoretical framework, Basu model produces biased estimations of the relations between accounting net income and both good and bad news. In section 5, we have developed an alternative model that follows our theoretical framework and controls the biases located in section 4. In this section, we compare the empirical performance of the two models to test if the biases that we have located from the theoretical model are also observable on real data.

\subsection{Sample and data.}

The empirical tests of this paper rely on a sample composed by all the non-financial firms on Standard and Poor's Compustat for the years 1962 to 2009 with non-missing values for the variables net income and book value. Market data are obtained from the Center for Research in Security Prices (CRSP) data file. Those observations with missing data for return variables are also removed from the sample.

The final sample is composed by 95,998 observations, corresponding to 8,077 firms.

\subsection{Variables.}

The dependent variable of both models is accounting net income $\left(A N I_{t}\right)$, computed as net income before extraordinary items and normalized by the market value of equity at the beginning of the period. For Basu Model, we compute annual market returns $\left(R_{t}\right)$ as the total variation in equity market value during the period, divided by the market value of equity at the beginning of the period. The dummy variable $d_{t}$ will be equal to one if the value of the market return for the same period is negative. 
For the alternative model, we have computed the book-to-market ratio as the accounting value of stockholders equity divided by the market value of equity, both measured at the beginning of the period. Regarding the good news measure of a given year $\left(R_{t}^{+}\right)$, it has been calculated as the sum of all the positive monthly variations in the market value of equity occurred during the year $t$, and divided by the market value of equity at the beginning of period t. Similarly, the bad news measure $\left(R_{t}^{-}\right)$is computed as the sum of all the negative monthly variations in the market value of equity occurred during the year $t$, divided by the market value of equity at the beginning of the period.

Consequently, the sum of the good news and the bad news measures is exactly equal to the market returns measure employed in Basu model.

Although the aggregation effect is not likely to be completely removed using the monthly variations, because it is likely that multiple economic events could impact the month's return, the effect of the aggregation bias can be expected to be lower than using annual returns. A possible alternative to our measure could be the use of market value variations for smaller periods (for example, daily variations), what would reduce the aggregation effect. However, these variations of shorter periods have other problems, such as the stronger influence of the noisy variations in market prices.

To eliminate the potential effect of extreme observations, we have winsorized all the former variables at their top and bottom percentiles.

\subsection{Results.}

\subsubsection{Descriptive statistics.}

The descriptive statistics of the variables of the two models are reported on Table 1. Panel A of Table 1 shows the mean, standard deviation and percentiles of the variables for the full sample. The reported means and medians are of similar magnitude to the results of other previous works (for instance, García-Lara et al. 2009; Khan and Watts 2009). Additionally, these statistics show that earnings are negatively skewed and returns are positively skewed, as documented in previous research.

In addition to the descriptive statistics of the full sample, we also report the descriptive statistics for those observations with positive and negative values for market returns on panels B and C, respectively. The proportions of positive and negative returns in our sample are 55 and 45 per cent, respectively (similar to previous works as, for example, Basu 1997; García-Lara et al. 2009). The comparison of the descriptive statistics of the two subsamples shows that the observations with positive returns are associated to 
higher values of accounting net income, book-to-market ratio and good news.

Additionally, the standard deviations of the market return measures (total market return, good news and bad news) are also higher for the subsample with positive market returns. Table 2 reports the correlation coefficients between each pair of variables. Following the same scheme, we report the correlation coefficients for the whole sample (panel A), the correlations for the sub-sample of positive returns (panel B) and the correlations for the negative returns sub-sample (panel C).

\subsubsection{Cross-section comparison of the models.}

In this section, we compare the results of the cross-sectional comparison of the two models. The results of the estimation of these models are reported on table 3. Panel A of table 3 shows the results of the Ordinary Least Squares estimation of the models ${ }^{3}$; Panel B summarizes the relations between accounting net income and both good and bad news, as well as the timely differentiation coefficient; finally, on Panel C, we estimate the biases in Basu model presented in Appendix 3 using the obtained coefficients for the alternative model and the values reported on tables 1 and 2 .

According to the theoretical background, the relation between accounting earnings and good news (captured by the coefficient $\beta_{0}$ in the Basu model and the coefficient $b_{0}$ in the alternative model) is expected to be a positive number. In the same sense, the relation between accounting earnings and bad news (captured by the sum of the coefficients $\beta_{0}$ and $\beta_{1}$ in the Basu model and the coefficient $b_{1}$ in the alternative model) is also expected to be positive. However, consistently with conditional conservatism, the influence of bad news is expected to be stronger and, therefore, the differential timely recognition coefficient ( $\beta_{1}$ in the Basu model and the sum of $b_{0}$ and $b_{1}$ in the alternative model) is also expected to be positive.

Focusing on the relation between accounting net income and good news, the results for the Basu model show a negative value for coefficient $\beta_{0}$, indicating that higher positive market returns are related to lower accounting earnings. This empirical result, albeit counterintuitive and against expected, it is not uncommon in practice (for example, Chung and Wynn 2008; García-Lara et al. 2009; Kung et al. 2010; Patatoukas and Thomas 2011). A possible explanation for this negative value is the presence of negative biases in the estimation of this relation in Basu model. Consistent with this

\footnotetext{
${ }^{3}$ We have also estimated the models using a two-way clustering method on firms and year for the errors, following Petersen (2009). The conclusions do not differ from those obtained with the OLS errors. These results are not tabulated, but they are available from the authors.
} 
possibility, the estimation for the coefficient $b_{0}$ is positive and significant, as expected. Moreover, panel $\mathrm{C}$ of table 3 reports the value of the two biases for the estimation of $\beta_{0}$, calculated according to the expressions (32) and (33) presented in Appendix C and using the estimates of the coefficients of the alternative model and the standard deviations and correlations reported on tables 1 and 2. Both biases result negative, indicating that Basu model underestimates the relation between accounting earnings and good news compared to the alternative model. However, although both biases are negative, the omitted variable bias has a little impact on the estimate of the coefficient, being more important the aggregation bias. The amount of the sum of the two biases is high enough to turn the positive relation obtained with the alternative model into a negative relation in Basu model. However, the observed bias is significantly higher than the expected bias, since the "expected" Basu estimate (computed as the sum of $b_{0}$ and the biases) is not as negative as the actual Basu estimate.

Regarding the estimation of the differential timeliness coefficient, Basu model obtains a significant value of 0.4049 , which is notably higher than the value obtained for the alternative model (0.2131), albeit this value is also significantly positive. If the alternative model really corrects the omitted variable bias and the aggregation bias, then these biases would be making Basu model to overestimate the differential timeliness coefficient. The values computed for the biases of this coefficient, according to expressions (34) and (35), are consistent with this idea: although the omitted variable bias is negative, its magnitude is smaller than the magnitude of the aggregation bias, which is positive ${ }^{4}$. Nevertheless, although the sum of the two biases is positive, it is of lower magnitude (0.0066), because the omitted variable bias and the aggregation bias exhibit opposite effects. The expected Basu coefficient is, therefore, significantly lower than the actual $\beta_{1}$.

\footnotetext{
${ }^{4}$ Givoly et al. (2007) indicate that the aggregation effect introduce introduces a negative bias in the estimation of $\beta_{1}$. They demonstrate this influence using simulated data. We have obtained that the aggregation effect has the opposite sign (it contributes to the overestimating of $\beta_{1}$ ). This result, however, is not incompatible with Givoly et al. (2007) demonstration, because they make their simulations generating good news and bad news independently. The consequence is that, for their simulated data, both good news and bad news are positively related to positive and negative values of market return. However, in actual data, we have obtained that our measures of good and bad news exhibit a strong negative correlation for the full sample (-0.5217). This negative correlation makes bad news to be negatively related to positive market returns $(-0.3402)$, what contributes to make positive the aggregation bias.
} 
The alternative model also includes the variable 1 minus the book-to-market ratio as an explanatory variable. The value obtained for this coefficient is significantly positive, as expected.

Finally, we can compare the explanatory power of the two models comparing the values of their adjusted $\mathrm{R}^{2}$. Using this measure, the alternative model exhibits a higher explanatory power than Basu model, since its adjusted $\mathrm{R}^{2}$ is 0.1639 while the adjusted $\mathrm{R}^{2}$ of Basu model is 0.1013 .

In summary, our results indicate that, for our full sample, Basu model underestimates the relation between good news and earnings and overestimates the relation between Basu model and bad news. In consequence, the timely differentiation coefficient is also biased upwards in Basu model. Our results also show that the omitted variable bias has a lower influence on the estimation of the coefficients than the aggregation bias and that the explanatory power of the alternative model is clearly higher than the explanatory power of the traditional Basu model.

However, although the differences in the estimation of the relations between the two models exhibit the same sign as expected according to our computation of the biases, the actual differences are of greater magnitude than expected.

\section{Comparison of the cross-sectional estimation of the models in subsamples with high aggregation bias}

Givoly et al. (2007) show that the effect of the aggregation bias on the differential timeliness coefficient is more visible when the good news and the bad news offset each other, and it is more moderated when the returns are dominated by extreme values of good news or extreme values of bad news. Consistent with this idea, we expect the aggregation bias to be more evident for those companies with streams of good and bad news of similar magnitude, that is to say, for those companies whose market returns are near zero.

In table 4, we compare the estimates of the two models for successive sub-samples of companies for which we have removed the observations with extreme values of market returns. These samples are formed by the observations with an absolute value of market returns lower than 50\%, 40\%, 30\%, 20\%, 10\% and 5\%, respectively. The number of observations for these intervals range from 66,307 for the widest (around the 70 per cent 
of the observations) to 8,978 (around the 10 per cent of the observations) for the narrowest.

The results reported on table 4 show a significantly positive relation between good news and accounting net income increases for all the intervals. Comparing the positive values obtained for $\beta_{0}$ in all the intervals with the significantly negative value obtained for the full sample, we can conclude that the negative bias produced in the estimation of this coefficient for the full sample can be attributed to the particular behaviour of the observations with extreme market returns.

Regarding the differential timeliness coefficient $\beta_{1}$, it decreases as the width of the interval is reduced, as expected according to the aggregation bias effect. The value of $\beta_{1}$ for the first interval (returns between $-50 \%$ and $+50 \%$ ) is 0.2032 and, although it is significantly positive, it is much smaller than the value obtained for the full sample (0.4049). This reduction of nearly the 50 per cent of the value of the coefficient is produced by the elimination of the 30 per cent of the observations with extreme values of market returns. Consequently, this result indicates that the extreme market returns observations have a strong influence in the estimated value of $\beta_{1}$.

As we reduce the width of the interval around zero, the values of $\beta_{1}$ become lower, and they even result negative for the two smallest intervals, being significant the last one. This result confirms Givoly et al.’s argument about the effect of the aggregation effect on Basu model.

Finally, the elimination of the extreme returns reduces significantly the explanatory power of Basu model: from an initial value of 0.1013 for the full sample, the value of the adjusted $\mathrm{R}^{2}$ drops to 0.0444 for the interval of 50 per cent. This value is even lower if we reduce the width of the interval around zero. These results show, in conclusion, that the values we have obtained in the estimation of Basu model for the full sample are strongly determined by the observations with extreme values of market returns.

The results for the alternative model, however, are significantly different. Parameter $b_{0}$ results positive for all the intervals, being significant in all the cases except for the two smallest intervals (the value for the smallest interval is significant at the 10 per cent level). In addition to the positive sign, the most relevant characteristic is the stability of the coefficient across all the intervals, with the only exception of the interval of returns between -10 per cent and +10 per cent, for which the value of the coefficient is smaller. 
The behaviour of the coefficient $b_{1}$ is very similar: it presents a significantly positive coefficient for all the coefficients (included the smallest ones), and it remains stable around the value of 0.25 for all the intervals.

The difference of coefficients $b_{1}$ and $b_{0}$ measures the differential timely recognition between bad and good news for this model. Contrary to Basu model, we can observe that the value of this difference does not vary as we eliminate the observations with extreme market returns, and it remains stable around 0.20. In addition to its stability across all these intervals, the coefficient is also very similar to the value obtained for the full sample, showing that the coefficients of the alternative model are not so strongly determined by the extreme values of market returns.

Finally, the explanatory power of the model drops as we eliminate observations, but the decrements in the value of the adjusted $\mathrm{R}^{2}$ are much less important than those observed for the Basu model. Thus, the value of the adjusted $\mathrm{R}^{2}$ is 0.1639 for the full sample, and the value for the intervals range from 0.1520 (for the interval of $A B S\left(R_{t}\right)<50 \%$ ) to 0.1371 (for the interval of $A B S\left(R_{t}\right)<5 \%$ ); that is, the reduction in the adjusted $\mathrm{R}^{2}$ from the total sample to the smallest interval is less than a 3 per cent. Consequently, the explanatory power of the model is not significantly affected by the elimination of the extreme return observations.

In conclusion, the alternative model reveals itself as a method to estimate conditional conservatism which is clearly more robust to the aggregation bias than the traditional Basu model. Besides, their results seem less influenced by the observations of extreme returns than those of Basu model.

Panel B of table 4 presents the estimated values of the two biases (omitted variable bias and aggregation bias) taking as "true” relations between accounting net income and both good and bad news the coefficients obtained for the alternative model and using the formulae presented in the Appendix C. Then, we have calculated the "expected" values of the coefficients of Basu model, adding those biases to the estimations of $b_{0}$ (to obtain the "expected" $\beta_{0}$ ) or to the difference between $b_{1}$ and $b_{0}$ (to obtain the "expected" $\beta_{1}$ ). We can observe that the "expected" values of the Basu coefficients are very similar to the real ones: with the exceptions of the wider interval and the "expected" $\beta_{0}$ in the interval of 10 per cent, there is no significant difference between the actual estimate of Basu model and the expected value.

\subsubsection{Comparison of the time series performance of the models.}


To compare the time-series performance of the two models, we estimate them over the annual time-series of firms for which at least 8 years of data are available. To ensure that the number of periods with good news and bad news is sufficient, we removed all the companies that do not present a minimum of 3 years of each type. The resulting sample is composed by 80,949 observations from 4,244 different firms ${ }^{5}$.

Table 5 reports the descriptive statistics of the estimates of these firm-specific regressions for the two models. The columns at the left indicate the coefficients and the value of the adjusted $\mathrm{R}^{2}$ for the Basu model, while the columns at the right indicate the coefficients for the alternative model.

The comparison of the results of the two models lead to similar conclusions to those obtained with the cross-sectional analysis. The Basu estimate for the relation between good news and accounting earnings $\beta_{0}$ is, on average, of 0.034 . However, in 1,203 cases (around the 28 per cent of the sample) this coefficient obtains a negative value, being positive 3,041 cases (around the 72 per cent of the sample). Of these cases, only 782 are significant at the 5 per cent level (1,041 at the 10 per cent level). If we compare these results with the same coefficient for the alternative model $\left(b_{0}\right)$, we obtain results that are more consistent with the expectations according to the theoretical background: only 802 firms obtain a negative $b_{0}$ (around the 19 per cent of the sample) is 802 . From the 3,442 cases with a positive value, 1,468 are significant at the 5 per cent level $(1,849$ at the 10 per cent level). In summary, consistent with the results obtained for the cross-sectional analysis, these results are consistent with the idea that Basu model underestimates the relation between good news and accounting earnings.

Regarding the relation between bad news and accounting earnings, the results for Basu model (column $\beta_{0}+\beta_{1}$ ) indicate that the mean relation is 0.17 and the median relation is of 0.09 . The proportion of cases with a negative relation is around the 29 per cent $(1,234$ cases), being the remaining $(3,010)$ positive. From these cases, only the 16 per cent is significant at the 5 per cent level (23 per cent at the 10 per cent level). The results for the alternative model (parameter $b_{1}$ ) show a lower relation than that obtain with the Basu model (the mean coefficient is 0.12 and the median is 0.07 ). However, although

\footnotetext{
${ }^{5}$ The elimination of the firms with less than 3 positive or negative observations for $R_{t}$ is necessary to avoid the possibility that Basu model produces noisy estimates of the parameters as a consequence of the low number of observations of any of the two types. This condition implies the elimination of 246 firms (2,323 observations). This elimination, however, would not be necessary to test the alternative model. Therefore, the alternative model has the minor advantage that can be applied to a higher number of companies.
} 
the mean and median are nearer to zero, the number of observations with negative values for this parameter is lower: around the 20 per cent of the companies (870) obtained a negative $b_{1}$. Moreover, of the 80 per cent of the observations with positive values, around the 28 per cent is significant at the 5 per cent level (38 per cent at the 10 per cent level).

Regarding the differential timeliness coefficient $\left(\beta_{1}\right)$, around the 39 per cent of the firms obtain a negative value for this coefficient (this result is similar to that obtained by Givoly et al. (2007)). From the 60 per cent of firms with positive $\beta_{1}$, only the 14 per cent is significant at the 5 per cent level. In the alternative model, however, the proportion of firms with a negative differential timeliness coefficient (measured by the difference between $b_{1}$ and $b_{0}$ ) is slightly higher (near the 41 per cent). This higher proportion of negative values for the differential timeliness coefficient, however, is not unexpected if we take into account that the average relation between accounting earnings and good news is higher for the alternative model and the average relation between earnings and bad news is lower. Nevertheless, and despite this higher proportion of negative cases, the number of companies with a positive and significant differential timeliness coefficients is higher for the alternative model: more than the 26 per cent of the positive differential timeliness coefficients are significant at the 5 per cent level (14 per cent for Basu model).

Finally, table 5 reports the descriptive statistics of the values of the adjusted $R^{2}$ of the firm-specific estimations of the two models. The results indicate that the explanatory power of the alternative model is considerably higher than the explanatory power of the traditional Basu model: while Basu model obtains an average $\mathrm{R}^{2}$ of 0.19 (median of 0.16 ), the average $\mathrm{R}^{2}$ for the alternative model is over 0.41 (median of 0.42 ). In summary, the results of the firm-specific time-series estimations show that the alternative model performs on average better than Basu model: the relations between good news or bad news and accounting net income exhibit values that are consistent with the theory in a higher proportion of cases, and the explanatory power of the model is considerably higher than the explanatory power of Basu model.

\section{Conclusions.}

Since Basu (1997) proposed that accounting conservatism can be captured through the contemporaneous relationship between accounting net income and market returns, this 
has become the most widely employed method to measure accounting conservatism. In this paper, we employ a theoretical framework to evaluate the capability of Basu model to correctly capture the relations between accounting earnings and good and bad news, concluding that Basu estimates are very likely to be affected by two biases: (1) an omitted variable bias produced by the absence in the model of the book-to-marke ratio; and (2) an aggregation bias produced by the use of total market returns instead of separating good news from bad news.

In this paper we propose an alternative econometric model, derived from our theoretical framework, which is more robust to the two former biases.

The comparison of the performance of the two models using archival data indicates that the alternative model presents various advantages over Basu model. Thus, the crosssectional estimation of Basu model produces a negative value for the relation between good news and accounting earnings, what is counterintuitive, and can be interpreted as the product of negative biases in the estimation of this measure; the alternative model, on the other hand, produces a positive and significant value for this relation. Moreover, the explanatory capability of the alternative model, measured by the adjusted $\mathrm{R}^{2}$, is also higher for the alternative model.

When we estimate the Basu model in sub-samples with lower presence of extreme values of market returns, we observe that the relation between accounting earnings and positive market returns becomes positive, but the differential timeliness coefficient drops significantly, becoming even negative when we reduce the sample to the observations that are nearer to zero. Additionally, the explanatory power of Basu model also drops. These results confirm that the aggregation problem (more evident for the companies with returns near to zero) produce an important bias in Basu model. Besides, they also show that Basu estimates are strongly influenced by the companies with extreme market returns.

The performance of the alternative model for these samples is very different: the coefficients for the recognition of good news and for the recognition of bad news in accounting net income remains stable for all the intervals, and they are very similar to those obtained for the full sample. Moreover, the explanatory power is very similar in all the intervals and only slightly lower than that obtained for the full sample. All these results confirm that the alternative model is robust to the aggregation effect, but they 
also show that the observations with extreme market returns have a lower influence in the alternative model than in Basu model.

The comparison of the performance of the two models in time-series estimation is also favourable for the alternative model. Thus, it is less likely than Basu model to produce negative estimates of the relation between good news and earnings, and the proportion of significantly positive estimations for the relations between good or bad news and accounting earnings are higher. Moreover, the explanatory power for the alternative model is also higher than for Basu model (the mean adjusted $\mathrm{R}^{2}$ for the alternative model is 0.41, while the mean for Basu model is 0.19).

Finally, despite the advantages of the proposed model over the Basu model, we want to highlight that they share the same initial idea (bad news, proxied by negative variations in market value, are recorded timelier than good news, proxied by positive variations in market returns). Consequently, the alternative model also shares with Basu model other weaknesses that have been indicated by other authors, such as the simultaneity problem of the relationship between earnings and stock returns (Dietrich et al. 2007), the reliance on market efficiency, the effect of the nature of the economic events on the estimates of the model (Givoly et al. 2007), or the small share effect (Patatoukas and Thomas 2011). Consequently, our proposed model is preferable to Basu model, but that does not imply that it is free from these other problems. Their results must be considered, then, in relation to that limitation. 


\section{Appendix A. $\hat{\boldsymbol{\beta}}_{0}$ is a biased estimator of $\overline{\beta^{+}}$}

In this appendix, we demonstrate that $\hat{\beta}_{0}$ is a biased estimator of $\overline{\beta^{+}}$, except if very restrictive conditions are met.

The probability limit of $\hat{\beta}_{0}$ can be obtained as:

$p \lim \hat{\beta}_{0}=\frac{\operatorname{Cov}\left(\frac{A N I_{t}}{M_{t-1}}, R_{t} \mid R_{t} \geq 0\right)}{\operatorname{Var}\left(R_{t} \mid R_{t} \geq 0\right)}$

We start calculating the value of the numerator, that is, the covariance between accounting net income and market returns, conditioned on that market return is positive. To obtain the value of this covariance, we substitute $A N I_{t}$ by its value according to equation(7):

$$
\begin{aligned}
& \operatorname{Cov}\left(\frac{A N I_{t}}{M_{t-1}}, R_{t} \mid R_{t} \geq 0\right)= \\
& =\operatorname{Cov}\left(\frac{U C_{t}}{M_{t-1}}+\delta_{t} \cdot \frac{M_{t-1}-B_{t-1}}{M_{t-1}}+\overline{\beta_{t}^{+}} \cdot R_{t}+\left(\overline{\beta_{t}^{-}}-\overline{\beta_{t}^{+}}\right) \cdot R_{t}^{-}+\xi_{t}, R_{t} \mid R_{t} \geq 0\right)= \\
& =\underbrace{\operatorname{Cov}\left(\frac{U C_{t}}{M_{t-1}}, R_{t} \mid R_{t} \geq 0\right)}_{a}+\underbrace{\operatorname{Cov}\left(\delta_{t} \cdot \frac{M_{t-1}-B_{t-1}}{M_{t-1}}, R_{t} \mid R_{t} \geq 0\right)}_{b}+ \\
& \underbrace{\operatorname{Cov}\left(\overline{\beta_{t}^{+}} \cdot R_{t}, R_{t} \mid R_{t} \geq 0\right)}_{c}+\underbrace{\operatorname{Cov}\left(\left(\overline{\beta_{t}^{-}}-\overline{\beta_{t}^{+}}\right) \cdot R_{t}^{-}, R_{t} \mid R_{t} \geq 0\right)}_{d}+\underbrace{\operatorname{Cov}\left(\xi_{t}, R_{t} \mid R_{t} \geq 0\right)}_{e}
\end{aligned}
$$

Expression $a$ is the covariance between the unconditional conservatism of period $t$ and the market returns of that period. By definition, unconditional conservatism is unrelated to the economic gains and losses of the same period, so this covariance is equal to zero. Next, we calculate the value of expression $b$. Simplifying it, we obtain:

$$
\operatorname{Cov}\left(\delta_{t} \cdot \frac{M_{t-1}-B_{t-1}}{M_{t-1}}, R_{t} \mid R_{t} \geq 0\right)=-\delta_{t} \cdot \operatorname{Cov}\left(\frac{B_{t-1}}{M_{t-1}}, R_{t} \mid R_{t} \geq 0\right)
$$

Regarding expression $c$, it is the covariance of parameter $\overline{\beta_{t}^{+}}$multiplied by market returns with market returns. The result is the product of the parameter by the variance of market returns:

$$
\operatorname{Cov}\left(\overline{\beta_{t}^{+}} \cdot R_{t}, R_{t} \mid R_{t} \geq 0\right)=\overline{\beta^{+}} \cdot \operatorname{Var}\left(R_{t} \mid R_{t} \geq 0\right)
$$


Regarding expression $d$ we can extract the difference between the two betas, obtaining that the value of $d$ can be rewritten as:

$$
\operatorname{Cov}\left(\left(\overline{\beta_{t}^{-}}-\overline{\beta_{t}^{+}}\right) \cdot R_{t}^{-}, R_{t} \mid R_{t} \geq 0\right)=\left(\overline{\beta^{-}}-\overline{\beta^{+}}\right) \cdot \operatorname{Cov}\left(R_{t}^{-}, R_{t} \mid R_{t} \geq 0\right)
$$

Finally, expression $e$ will be equal to zero because $\xi_{t}$ is independent of $R_{t}$.

Substituting the obtained values of $a, b, c, d$ and $e$ in equation (19), we obtain that $\hat{\beta}_{0}$ converges in probability to:

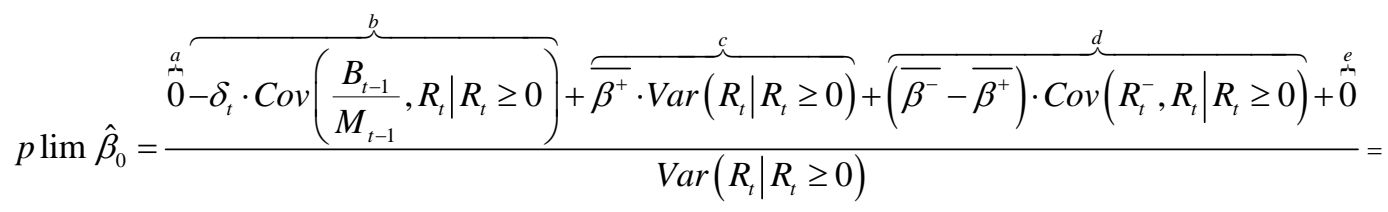

$$
\begin{aligned}
& =\overline{\beta^{+}}-\underbrace{\frac{\delta_{t} \cdot \operatorname{Cov}\left(\frac{B_{t-1}}{M_{t-1}}, R_{t} \mid R_{t} \geq 0\right)}{\operatorname{Var}\left(R_{t} \mid R_{t} \geq 0\right)}}_{\text {Omitted variable bias }}+\underbrace{\left(\overline{\beta^{-}}-\overline{\beta^{+}}\right) \cdot \frac{\operatorname{Cov}\left(R_{t}^{-}, R_{t} \mid R_{t} \geq 0\right)}{\operatorname{Var}\left(R_{t} \mid R_{t} \geq 0\right)}}_{\text {Aggregation bias }}= \\
& =\overline{\beta^{+}}-\underbrace{\delta_{t} \cdot r\left(\frac{B_{t-1}}{M_{t-1}}, R_{t} \mid R_{t} \geq 0\right) \frac{\operatorname{Dev}\left(\frac{B_{t-1}}{M_{t-1}} \mid R_{t} \geq 0\right)}{\operatorname{Dev}\left(R_{t} \mid R_{t} \geq 0\right)}}_{\text {Omitted variable bias }}+\underbrace{\left(\overline{\beta^{-}}-\overline{\beta^{+}}\right) \cdot r\left(R_{t}^{-}, R_{t} \mid R_{t} \geq 0\right) \frac{\operatorname{Dev}\left(R_{t}^{-} \mid R_{t} \geq 0\right)}{\operatorname{Dev}\left(R_{t} \mid R_{t} \geq 0\right)}}_{\text {Aggreation bias }}
\end{aligned}
$$

Where $r$ represents the Pearson correlation coefficient and $\operatorname{Dev}(\cdot)$ is the standard deviation operator.

In consequence, the OLS estimation of the parameter $\hat{\beta}_{0}$ will be a biased estimation of the real average influence of good news on earnings, unless the sum of the second and the third addends of expression (24) is equal to zero. This will happen if the two biases (the omitted variable bias and the aggregation bias) are simultaneously equal to zero or if they have values that are different from zero but those values offset each other. We consider this last situation very unlikely, because the two biases proceed from two different sources. Therefore, we are going to discuss the conditions for the two biases to be equal to zero.

We have named the first addend the Omitted variable bias, because it is produced by the absence of the book-to-market ratio in Basu model. The sign of this bias will depend on the covariance between the book-to-market ratio and the market return of the period, so it will be equal to zero if there is no relation between market returns and the book-tomarket ratio. 
The second added is named the Aggregation bias, because it is produced by the covariance between the bad news and the total return of the period in those periods with positive returns. For this second bias to be equal to zero, at least one of the two following conditions should be met:

Condition 1: $\overline{\beta^{-}}=\overline{\beta^{+}}$. In this case, there will be no differentiation in the recognition of good and bad news and, consequently, there would be no evidence of accounting conservatism.

Condition 2: $\operatorname{Cov}\left(R_{t}^{-}, R_{t} \mid R_{t} \geq 0\right)=0$. This condition implies the absence of relation between the market return of the period $\left(R_{t}\right)$ and the bad news of the period $\left(R_{t}^{-}\right)$. Next, we analyze in which cases condition 2 is fulfilled. For doing it, we can substitute $R_{t}$ by the sum of good news and bad news, divided by the market value of equity at the beginning of the period:

$$
\begin{aligned}
& \operatorname{Cov}\left(R_{t}^{-}, R_{t} \mid R_{t} \geq 0\right)=0 \Leftrightarrow \operatorname{Cov}\left(R_{t}^{-}, R_{t}^{-}+R_{t}^{+} \mid R_{t} \geq 0\right)=0 \Leftrightarrow \\
& \Leftrightarrow \operatorname{Var}\left(R_{t}^{-} \mid R_{t} \geq 0\right)+\operatorname{Cov}\left(R_{t}^{-}, R_{t}^{+} \mid R_{t} \geq 0\right)=0 \Leftrightarrow \\
& \Leftrightarrow \operatorname{Var}\left(R_{t}^{-} \mid R_{t} \geq 0\right)=-\operatorname{Cov}\left(R_{t}^{-}, R_{t}^{+} \mid R_{t} \geq 0\right)
\end{aligned}
$$

If we substitute the value of the covariance by the product of the standard deviations and the Pearson correlation coefficient, we can conclude that:

$$
\begin{aligned}
& \operatorname{Cov}\left(R_{t}^{-}, R_{t} \mid R_{t} \geq 0\right)=0 \Leftrightarrow \\
& \Leftrightarrow \operatorname{Var}\left(R_{t}^{-} \mid R_{t} \geq 0\right)=-r\left(R_{t}^{-}, R_{t}^{+} \mid R_{t} \geq 0\right) \cdot \operatorname{Dev}\left(R_{t}^{-} \mid R_{t} \geq 0\right) \cdot \operatorname{Dev}\left(R_{t}^{+} \mid R_{t} \geq 0\right) \Leftrightarrow \\
& \Leftrightarrow r\left(R_{t}^{-}, R_{t}^{+} \mid R_{t} \geq 0\right)=-\frac{\operatorname{Dev}\left(R_{t}^{-} \mid R_{t} \geq 0\right)}{\operatorname{Dev}\left(R_{t}^{+} \mid R_{t} \geq 0\right)}
\end{aligned}
$$

Where $\operatorname{Dev}($.$) denotes the standard deviation operator. We can conclude that the$ aggregation bias can take the following values:

a) If the correlation between good and bad news, conditioned on the positive values of returns, is exactly equal to minus the proportion of the standard deviation of bad news over the standard deviation of good news (both conditioned on the positive values of returns), there will be no aggregation bias error.

b) If that correlation is higher than minus the proportion of the standard deviations, the aggregation bias will be positive, and Basu model will be overestimating (if we do not take into account the omitted variable bias) the relation between accounting net income and good news. This will happen, for instance, for any 
positive correlation between good news and bad news or for the absence of correlation between them.

c) If the correlation is lower than minus the proportion of the standard deviations, the aggregation bias will be negative, and Basu model will be underestimating (without taking into account the omitted variable bias) the relation between accounting net income and good news.

The actual sign of the bias is an empirical issue. However, it does not seem likely that this bias will be equal to zero because, to our knowledge, there is no logical reason for expecting that good news and bad news will exhibit the required correlation. 


\section{Appendix B. $\hat{\beta}_{1}$ is a biased estimator of $\overline{\beta^{-}}-\overline{\beta^{+}}$}

The following expression shows the probability limit of $\hat{\beta}_{1}$ :

$p \lim \hat{\beta}_{1}=\frac{\operatorname{Cov}\left(\frac{A N I_{t}}{M_{t-1}}, R_{t} \mid R_{t}<0\right)}{\operatorname{Var}\left(R_{t} \mid R_{t}<0\right)}-\frac{\operatorname{Cov}\left(\frac{A N I_{t}}{M_{t-1}}, R_{t} \mid R_{t} \geq 0\right)}{\operatorname{Var}\left(R_{t} \mid R_{t} \geq 0\right)}$

In Appendix A, we have demonstrated that:

$$
\frac{\operatorname{Cov}\left(\frac{A N I_{t}}{M_{t-1}}, R_{t} \mid R_{t} \geq 0\right)}{\operatorname{Var}\left(R_{t} \mid R_{t} \geq 0\right)}=\overline{\beta^{+}}-\underbrace{\frac{\delta_{t} \cdot \operatorname{Cov}\left(\frac{B_{t-1}}{M_{t-1}}, R_{t} \mid R_{t} \geq 0\right)}{\operatorname{Var}\left(R_{t} \mid R_{t} \geq 0\right)}}_{\text {Omitted variable bias }}+\underbrace{\left(\overline{\beta^{-}}-\overline{\beta^{+}}\right) \cdot \frac{\operatorname{Cov}\left(R_{t}^{-}, R_{t} \mid R_{t} \geq 0\right)}{\operatorname{Var}\left(R_{t} \mid R_{t} \geq 0\right)}}_{\text {Aggregation bias }}
$$

Analogously, it can be also demonstrated that:

$$
\frac{\operatorname{Cov}\left(\frac{A N I_{t}}{M_{t-1}}, R_{t} \mid R_{t}<0\right)}{\operatorname{Var}\left(R_{t} \mid R_{t}<0\right)}=\overline{\beta^{+}}-\underbrace{\frac{\delta_{t} \cdot \operatorname{Cov}\left(\frac{B_{t-1}}{M_{t-1}}, R_{t} \mid R_{t}<0\right)}{\operatorname{Var}\left(R_{t} \mid R_{t}<0\right)}}_{\text {Omitted variable bias }}+\underbrace{\left(\overline{\beta^{-}}-\overline{\beta^{+}}\right) \cdot \frac{\operatorname{Cov}\left(R_{t}^{-}, R_{t} \mid R_{t}<0\right)}{\operatorname{Var}\left(R_{t} \mid R_{t}<0\right)}}_{\text {Aggregation bias }}
$$

Consequently, the probability limit of $\hat{\beta}_{1}$ can be obtained as:

$p \lim \hat{\beta}_{1}=$

$$
\begin{aligned}
& =\overline{\beta^{+}}-\underbrace{\frac{\delta_{t} \cdot \operatorname{Cov}\left(\frac{B_{t-1}}{M_{t-1}}, R_{t} \mid R_{t}<0\right)}{\operatorname{Var}\left(R_{t} \mid R_{t}<0\right)}}_{\text {Omitted variable bias }}+\underbrace{\left(\overline{\beta^{-}}-\overline{\beta^{+}}\right) \cdot \frac{\operatorname{Cov}\left(R_{t}^{-}, R_{t} \mid R_{t}<0\right)}{\operatorname{Var}\left(R_{t} \mid R_{t}<0\right)}}_{\text {Agaregation bias }}-\overline{\beta^{+}}+ \\
& +\underbrace{\frac{\delta_{t} \cdot \operatorname{Cov}\left(\frac{B_{t-1}}{M_{t-1}}, R_{t} \mid R_{t} \geq 0\right)}{\operatorname{Var}\left(R_{t} \mid R_{t} \geq 0\right)}}_{\text {Omitted variable bias }}-\underbrace{\left(\overline{\beta^{-}}-\overline{\beta^{+}}\right) \cdot \frac{\operatorname{Cov}\left(R_{t}^{-}, R_{t} \mid R_{t} \geq 0\right)}{\operatorname{Var}\left(R_{t} \mid R_{t} \geq 0\right)}}_{\text {Aggregation bias }}=
\end{aligned}
$$$$
=\left(\overline{\beta^{-}}-\overline{\beta^{+}}\right) \cdot \underbrace{\left[\frac{\operatorname{Cov}\left(R_{t}^{-}, R_{t} \mid R_{t}<0\right)}{\operatorname{Var}\left(R_{t} \mid R_{t}<0\right)}-\frac{\operatorname{Cov}\left(R_{t}^{-}, R_{t} \mid R_{t} \geq 0\right)}{\operatorname{Var}\left(R_{t} \mid R_{t} \geq 0\right)}\right]}_{\text {Aggregation bias }}-
$$

$$
\underbrace{-\delta_{t} \cdot\left[\frac{\operatorname{Cov}\left(\frac{B_{t-1}}{M_{t-1}}, R_{t} \mid R_{t}<0\right)}{\operatorname{Var}\left(R_{t} \mid R_{t}<0\right)}-\frac{\operatorname{Cov}\left(\frac{B_{t-1}}{M_{t-1}}, R_{t} \mid R_{t} \geq 0\right)}{\operatorname{Var}\left(R_{t} \mid R_{t} \geq 0\right)}\right]}_{\text {Omitted variable bias }}
$$

Alternatively, the former expression can be also written as: 


$$
\begin{aligned}
& p \lim \hat{\beta}_{1}=\left(\overline{\beta^{+}}-\overline{\beta^{-}}\right) \cdot \underbrace{\left[r\left(R_{t}^{-}, R_{t} \mid R_{t}<0\right) \frac{\operatorname{Dev}\left(R_{t}^{-} \mid R_{t}<0\right)}{\operatorname{Dev}\left(R_{t} \mid R_{t}<0\right)}-r\left(R_{t}^{-}, R_{t} \mid R_{t} \geq 0\right) \frac{\operatorname{Dev}\left(R_{t}^{-} \mid R_{t} \geq 0\right)}{\operatorname{Dev}\left(R_{t} \mid R_{t} \geq 0\right)}\right]}_{\text {Aggregation bias }}- \\
& \underbrace{-\delta_{t} \cdot\left[r\left(\frac{B_{t-1}}{M_{t-1}}, R_{t} \mid R_{t}<0\right) \frac{\operatorname{Dev}\left(\frac{B_{t-1}}{M_{t-1}} \mid R_{t}<0\right)}{\operatorname{Dev}\left(R_{t} \mid R_{t}<0\right)}-r\left(\frac{B_{t-1}}{M_{t-1}}, R_{t} \mid R_{t} \geq 0\right) \frac{\operatorname{Dev}\left(\frac{B_{t-1}}{M_{t-1} \mid} \mid R_{t} \geq 0\right)}{\operatorname{Dev}\left(R_{t} \mid R_{t} \geq 0\right)}\right]}_{\text {Omitted variable bias }}-
\end{aligned}
$$

We obtain that $\hat{\beta}_{1}$, as estimator of $\left(\overline{\beta^{-}}-\overline{\beta^{+}}\right)$, is also affected by two biases: an omitted variable bias and an aggregation bias. However, differently from $\hat{\beta}_{0}$, the aggregation bias has a multiplicative effect, while the omitted variable bias has an additive effect. As for $\hat{\beta}_{0}$, we could conclude that $\hat{\beta}_{1}$ is an unbiased estimator of $\left(\overline{\beta^{-}}-\overline{\beta^{+}}\right)$if the two biases cancel each other. However, the different nature and the different effect of the two biases make this situation unlikely.

The omitted variable bias is produced by the difference in the relation between market returns and the ratio book-to-market when returns are below zero and when returns are above zero. If the relation between the book-to-market ratio and returns is approximately the same for the years with positive returns as for the years with negative returns, this bias will tend to be null. However, if the relation between both variables is different for positive and negative values of market returns, it will produce a bias in the estimation of the differential timeliness of losses.

The aggregation bias has a multiplicative effect, and it depends on the difference in the influence of bad news on market returns in the years with negative returns compared to the years with positive returns. The aggregation bias can have the following effects on the estimation of Basu's $\hat{\beta}_{1}$ :

a) If Aggregation bias=1, there will be no aggregation effect and $\hat{\beta}_{1}$ will be (without taking into account the omitted variable bias) an unbiased estimator of $\left(\overline{\beta^{-}}-\overline{\beta^{+}}\right)$

b) If Aggregation bias $<1$, Basu model will be underestimating the difference in the timely recognition of losses (in absence of the omitted variable bias), that is, Basu model would be underestimating conditional conservatism. 
c) Finally, if Aggregation bias>1, Basu model will be overestimating conditional conservatism (in absence of omitted variable bias).

Although the actual value of the Aggregation bias is an empirical issue, we find unlikely that the relation between bad news and negative returns minus the relation between good news and positive returns was exactly equal to one. Consequently, we expect $\hat{\beta}_{1}$ to be affected by the aggregation bias. 


\section{Appendix C. Calculation of the different biases in Basu model.}

In this appendix we summarize the results obtained in appendixes A and B, presenting the formulae that can be employed to calculate the biases in the estimates of Basu model. We divide these formulae into two groups: biases of the relation between accounting net income and good news and biases of the differential timeliness coefficient.

Biases of the relation between accounting net income and good news.

In appendix $\mathrm{A}$, we have shown that parameter $\beta_{0}$ is likely to be a biased estimator of the true relation between net income and good news because of two biases. These biases are the following:

Omitted variable bias: $-\delta_{t} \cdot r\left(\frac{B_{t-1}}{M_{t-1}}, R_{t} \mid R_{t} \geq 0\right) \frac{\operatorname{Dev}\left(\frac{B_{t-1}}{M_{t-1}} \mid R_{t} \geq 0\right)}{\operatorname{Dev}\left(R_{t} \mid R_{t} \geq 0\right)}$

Aggregation bias: $\left(\overline{\beta^{-}}-\overline{\beta^{+}}\right) \cdot r\left(R_{t}^{-}, R_{t} \mid R_{t} \geq 0\right) \frac{\operatorname{Dev}\left(R_{t}^{-} \mid R_{t} \geq 0\right)}{\operatorname{Dev}\left(R_{t} \mid R_{t} \geq 0\right)}$

\section{Biases of the differential timeliness coefficient.}

In appendix $\mathrm{B}$, we obtain that Basu's $\beta_{1}$ can be a biased estimator of the real difference in the recognition of losses and gains because of two biases. We can obtain the amount of this biases from these expressions:

Omitted variable bias:

$-\delta_{t} \cdot\left[r\left(\frac{B_{t-1}}{M_{t-1}}, R_{t} \mid R_{t}<0\right) \frac{\operatorname{Dev}\left(\frac{B_{t-1}}{M_{t-1}} \mid R_{t}<0\right)}{\operatorname{Dev}\left(R_{t} \mid R_{t}<0\right)}-r\left(\frac{B_{t-1}}{M_{t-1}}, R_{t} \mid R_{t} \geq 0\right) \frac{\operatorname{Dev}\left(\frac{B_{t-1}}{M_{t-1} \mid} \mid R_{t} \geq 0\right)}{\operatorname{Dev}\left(R_{t} \mid R_{t} \geq 0\right)}\right]$

Aggregation bias:

$$
\left(\overline{\beta^{-}}-\overline{\beta^{+}}\right) \cdot\left[r\left(R_{t}^{-}, R_{t} \mid R_{t}<0\right) \frac{\operatorname{Dev}\left(R_{t}^{-} \mid R_{t}<0\right)}{\operatorname{Dev}\left(R_{t} \mid R_{t}<0\right)}-r\left(R_{t}^{-}, R_{t} \mid R_{t} \geq 0\right) \frac{\operatorname{Dev}\left(R_{t}^{-} \mid R_{t} \geq 0\right)}{\operatorname{Dev}\left(R_{t} \mid R_{t} \geq 0\right)}-1\right]
$$


Table 1. Descriptive statistics

\begin{tabular}{|c|c|c|c|c|c|}
\hline \multicolumn{6}{|c|}{ Panel A. Whole sample (N=95,998) } \\
\hline & $\mathrm{ANI}_{\mathrm{t}}$ & $\mathrm{R}_{\mathrm{t}}$ & $\mathrm{BTM}_{\mathrm{t}}$ & $R_{t}^{+}$ & $R_{t}^{-}$ \\
\hline Mean & 0.0026 & 0.2026 & 0.7782 & 0.8614 & -0.6502 \\
\hline Standard deviation & 0.2500 & 0.7695 & 0.7521 & 0.9365 & 0.4550 \\
\hline p5 & -0.4012 & -0.6489 & 0.0933 & 0.1452 & -1.4733 \\
\hline p25 & -0.0179 & -0.2347 & 0.3166 & 0.3341 & -0.8333 \\
\hline p50 & 0.0529 & 0.0517 & 0.5757 & 0.5642 & -0.5539 \\
\hline p75 & 0.0993 & 0.4013 & 0.9879 & 1.0000 & -0.3394 \\
\hline p95 & 0.2396 & 1.6130 & 2.1687 & 2.6366 & -0.1478 \\
\hline \multicolumn{6}{|c|}{ Panel B. Firm-year with positive $\mathrm{R}_{\mathrm{t}}(\mathrm{N}=52,856)$} \\
\hline & $\mathrm{ANI}_{\mathrm{t}}$ & $\mathrm{R}_{\mathrm{t}}$ & $\mathrm{BTM}_{\mathrm{t}}$ & $R_{t}^{+}$ & $R_{t}^{-}$ \\
\hline Mean & 0.0474 & 0.6283 & 0.8405 & 1.2085 & -0.5676 \\
\hline Standard deviation & 0.2297 & 0.7924 & 0.7985 & 1.1041 & 0.4939 \\
\hline p5 & -0.2873 & 0.0269 & 0.1103 & 0.2972 & -1.5526 \\
\hline p25 & 0.0295 & 0.1515 & 0.3458 & 0.5361 & -0.6949 \\
\hline p50 & 0.0746 & 0.3495 & 0.6212 & 0.8435 & -0.4232 \\
\hline p75 & 0.1272 & 0.7506 & 1.0630 & 1.4190 & -0.2568 \\
\hline p95 & 0.2929 & 2.3463 & 2.3612 & 3.5988 & -0.1113 \\
\hline \multicolumn{6}{|c|}{ Panel C. Firm-year with negative $\mathrm{R}_{\mathrm{t}}(\mathrm{N}=43,142)$} \\
\hline & $\mathrm{ANI}_{\mathrm{t}}$ & $\mathrm{R}_{\mathrm{t}}$ & $\mathrm{BTM}_{\mathrm{t}}$ & $R_{t}^{+}$ & $R_{t}^{-}$ \\
\hline Mean & -0.0523 & -0.3189 & 0.7019 & 0.4360 & -0.7513 \\
\hline Standard deviation & 0.2626 & 0.2333 & 0.6834 & 0.3600 & 0.3785 \\
\hline p5 & -0.5119 & -0.7800 & 0.0780 & 0.1000 & -1.4115 \\
\hline p25 & -0.0746 & -0.4726 & 0.2857 & 0.2244 & -0.9221 \\
\hline p50 & 0.0235 & -0.2708 & 0.5255 & 0.3530 & -0.6892 \\
\hline p75 & 0.0648 & -0.1251 & 0.8934 & 0.5366 & -0.4950 \\
\hline p95 & 0.1505 & -0.0254 & 1.9221 & 1.0212 & -0.2879 \\
\hline
\end{tabular}


Table 2. Correlations matrix

\begin{tabular}{|c|c|c|c|c|c|}
\hline \multicolumn{6}{|c|}{ Panel A. Correlations for the full sample } \\
\hline & $\mathrm{ANI}_{\mathrm{t}}$ & $\mathrm{R}_{\mathrm{t}}$ & $\mathrm{BTM}_{\mathrm{t}}$ & $R_{t}^{+}$ & $R_{t}^{-}$ \\
\hline $\mathrm{ANI}_{\mathrm{t}}$ & & $0.1125 *$ & $-0.0503 *$ & $-0.0993 *$ & $0.3819 *$ \\
\hline $\mathrm{R}_{\mathrm{t}}$ & $0.3755 *$ & & $0.0824 *$ & $0.8546 *$ & $-0.0271 *$ \\
\hline $\mathrm{BTM}_{\mathrm{t}}$ & $0.2476 *$ & $0.1067 *$ & & $0.0614 *$ & $0.0110 *$ \\
\hline$R_{t}^{+}$ & $0.0698 *$ & $0.7136 *$ & $0.0067 *$ & & $-0.5217 *$ \\
\hline$R_{t}^{-}$ & $0.4376 *$ & $0.3359 *$ & $0.1352 *$ & $-0.3034 *$ & \\
\hline \multicolumn{6}{|c|}{ Panel B. Correlations for firm-year with positive $\mathrm{R}_{\mathrm{t}}(\mathrm{N}=52,856)$} \\
\hline & $\mathrm{ANI}_{\mathrm{t}}$ & $\mathrm{R}_{\mathrm{t}}$ & $\mathrm{BTM}_{\mathrm{t}}$ & $R_{t}^{+}$ & $R_{t}^{-}$ \\
\hline $\mathrm{ANI}_{\mathrm{t}}$ & & $-0.1094 *$ & $0.0409 *$ & $-0.2354 *$ & 0.3350 * \\
\hline $\mathrm{R}_{\mathrm{t}}$ & $0.6320 *$ & & $0.0242 *$ & $0.8951 *$ & $-0.3402 *$ \\
\hline BTM $_{t}$ & 0.3454 * & $-0.0275 *$ & & $0.0313 *$ & $-0.0359 *$ \\
\hline$R_{t}^{+}$ & $-0.1025 *$ & $0.7872 *$ & $-0.0631 *$ & & $-0.7003 *$ \\
\hline$R_{t}^{-}$ & $0.2484 *$ & $-0.1604 *$ & $0.0656 *$ & $-0.6622 *$ & \\
\hline \multicolumn{6}{|c|}{ Panel C. Correlations for firm-year with negative $R_{t}(N=43,142)$} \\
\hline & $\mathrm{ANI}_{\mathrm{t}}$ & $\mathrm{R}_{\mathrm{t}}$ & $\mathrm{BTM}_{\mathrm{t}}$ & $R_{t}^{+}$ & $R_{t}^{-}$ \\
\hline $\mathrm{ANI}_{\mathrm{t}}$ & & 0.3357 * & $-0.2109 *$ & $-0.2223 *$ & 0.4027 * \\
\hline $\mathrm{R}_{\mathrm{t}}$ & $0.4378 *$ & & $0.0941 *$ & 0.0977 * & $0.5228 *$ \\
\hline $\mathrm{BTM}_{\mathrm{t}}$ & $0.0835 *$ & $0.1551 *$ & & $0.0142 *$ & 0.0453 * \\
\hline$R_{t}^{+}$ & $-0.1658 *$ & $0.1880 *$ & $-0.0547 *$ & & $-.7699 *$ \\
\hline$R_{t}^{-}$ & $0.5024 *$ & $0.6032 *$ & $0.1747^{*}$ & $-0.5941 *$ & \\
\hline
\end{tabular}


Table 3. Cross sectional comparison of the models

\begin{tabular}{|c|c|c|c|c|c|}
\hline \multicolumn{4}{|c|}{ Basu model } & \multicolumn{2}{|c|}{ Alternative model } \\
\hline \multicolumn{6}{|c|}{ Panel A. Estimates of the models } \\
\hline & Coef. (S.E.) & $\mathbf{P}>\mathbf{t}$ & & Coef. (S.E.) & $\mathbf{P}>\mathbf{t}$ \\
\hline \multirow[t]{2}{*}{$\beta_{0}$} & -0.0318 & 0.0000 & & & \\
\hline & $(0.0013)$ & & & & \\
\hline \multirow[t]{2}{*}{$\alpha_{1}$} & -0.0001 & 0.9590 & & & \\
\hline & $(0.0023)$ & & & & \\
\hline \multirow[t]{2}{*}{$\beta_{1}$} & 0.4049 & 0.0000 & & & \\
\hline & $(0.0050)$ & & & & \\
\hline \multirow[t]{2}{*}{$b_{0}$} & & & & 0.0382 & 0.0000 \\
\hline & & & & $(0.0009)$ & \\
\hline \multirow[t]{2}{*}{$b_{1}$} & & & & 0.2513 & 0.0000 \\
\hline & & & & $(0.0019)$ & \\
\hline \multirow[t]{2}{*}{$a_{1}$} & & & & 0.0225 & 0.0000 \\
\hline & & & & $(0.0010)$ & \\
\hline \multirow[t]{2}{*}{ Constant } & 0.0673 & 0.0000 & & 0.1280 & 0.0000 \\
\hline & $(0.0013)$ & & & $(0.0013)$ & \\
\hline$F$ & 3609.65 & & & 6275.59 & \\
\hline $\operatorname{Adj} R^{2}$ & 0.1013 & & & 0.1639 & \\
\hline \multicolumn{6}{|c|}{ Panel B. Summary of relations } \\
\hline \multirow[t]{2}{*}{ Good news } & -0.0318 & 0.0000 & & 0.0382 & 0.0000 \\
\hline & $(0.0013)$ & & & $(0.0009)$ & \\
\hline \multirow[t]{2}{*}{ Bad news } & 0.3731 & 0.0000 & & 0.2513 & 0.0000 \\
\hline & $(0.0048)$ & & & $(0.0019)$ & \\
\hline \multirow[t]{2}{*}{ Difference } & 0.4049 & 0.0000 & & 0.2131 & 0.0000 \\
\hline & $(0.0050)$ & & & $(0.0016)$ & \\
\hline \multicolumn{6}{|c|}{ Panel C. Estimation of biases and comparison with real estimates } \\
\hline & $\begin{array}{l}\text { Real Basu } \\
\text { coefficient }\end{array}$ & OVB & $\mathrm{AB}$ & $\begin{array}{l}\text { Expected } \\
\text { Basu } \\
\text { coefficient }\end{array}$ & $C h i^{2}$ \\
\hline Good news & -0.0318 & -0.0006 & -0.0452 & -0.0075 & $524.57 *$ \\
\hline Difference & 0.4049 & -0.0062 & 0.0128 & 0.2196 & $862.62 *$ \\
\hline
\end{tabular}

This table reports the estimates of the two following models:

Basu model:

$$
A N I_{t}=\alpha_{0}+\alpha_{1} \cdot d_{t}+\beta_{0} \cdot R_{t}+\beta_{1} \cdot d_{t} \cdot R_{t}+\varepsilon_{t}
$$

Alternative model:

$$
A N I_{t}=a_{0}+a_{1} \cdot\left(1-B T M_{t-1}\right)+b_{0} \cdot R_{t}^{+}+b_{1} \cdot R_{t}^{-}+\varepsilon_{t}
$$

Where $A N I_{t}$ is the accounting net income of the year $t$ divided by the market value of equity at the beginning of the year $t ; R_{t}$ is the market rate of return of the year $t$; $d_{t}$ is a dummy variable that takes the value of 1 if $R_{t}$ is negative and 0 otherwise; $B T M_{t-1}$ is the book-to-market ratio at the beginning of period $t$; $R_{t}^{+}$is the sum of all the monthly positive variations in the market value of equity during the period $t$ 
divided by the market value of equity at the beginning of the year $t$; and $R_{t}^{-}$is the sum of all the monthly negative variations in the market value of equity during the year $t$ divided by the market value of equity at the beginning of the year $t$.

Panel A shows the estimates of the two models (standard errors in parentheses).

Panel B summarizes the relations between accounting net income and, respectively, good news (parameter $\beta_{0}$ for Basu model, and parameter $b_{0}$ for the alternative model), bad news (the sum of parameters $\beta_{0}+\beta_{1}$ for Basu model, and parameter $b_{1}$ for the alternative model), and the difference between the two relations (parameter $\beta_{1}$ for Basu model, and the difference $b_{1}$ - $b_{0}$ for the alternative model)

Panel $\mathrm{C}$ reports the estimated values of the omitted variable biases (OVB) and the aggregation biases (AB) for the two indicated relations, according to the expressions presented in Appendix $\mathrm{C}$, and using the estimates of the coefficients of the alternative model and the standard deviations and correlations reported on tables 1 and 2. It additionally shows the "expected Basu coefficient" calculated as the coefficients obtained for the alternative model plus the estimated biases. $\mathrm{Chi}^{2}$ is a test of the difference between the real Basu estimates and the expected Basu coefficients. 
Table 4. Cross sectional comparison of the models in subsamples with high aggregation bias

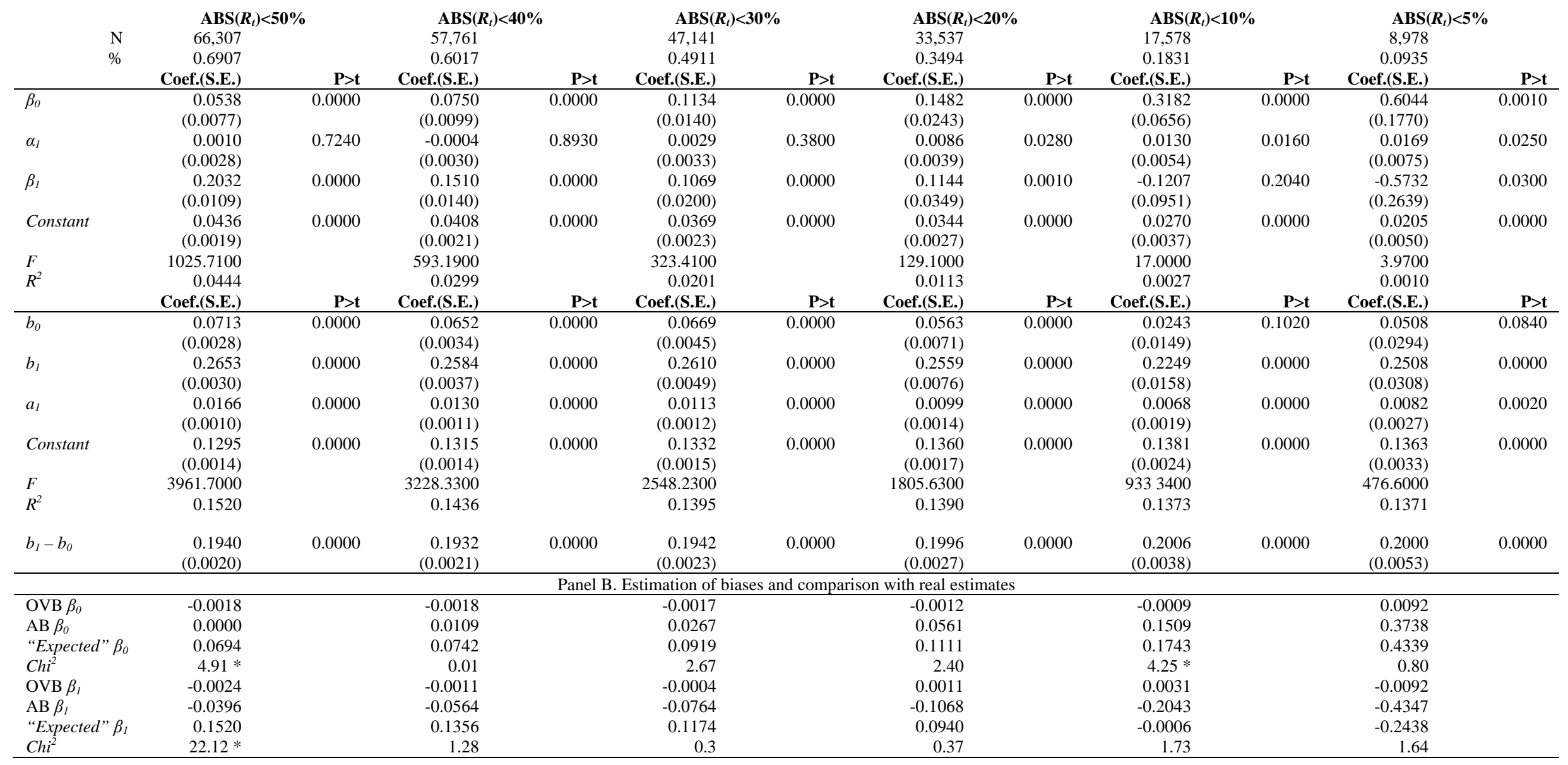

This table reports the estimates of the two following models:

Basu model: 
$A N I_{t}=\alpha_{0}+\alpha_{1} \cdot d_{t}+\beta_{0} \cdot R_{t}+\beta_{1} \cdot d_{t} \cdot R_{t}+\varepsilon_{t}$

Alternative model:

$$
A N I_{t}=a_{0}+a_{1} \cdot\left(1-B T M_{t-1}\right)+b_{0} \cdot R_{t}^{+}+b_{1} \cdot R_{t}^{-}+\varepsilon_{t}
$$

Where $A N I_{t}$ is the accounting net income of the year $t$ divided by the market value of equity at the beginning of the year $t$; $R_{t}$ is the market rate of return of the year $t$; $d_{t}$ is a dummy variable that takes the value of 1 if $R_{t}$ is negative and 0 otherwise; BTM $M_{t-1}$ is the book-to-market ratio at the beginning of period $t$; $R_{t}^{+}$is the sum of all the monthly positive variations in the market value of equity during the period $t$ divided by the market value of equity at the beginning of the year $t$; and $R_{t}^{-}$is the sum of all the monthly negative variations in the market value of equity during the year $t$ divided by the market value of equity at the beginning of the year $t$. The estimates are reported for various sub-samples defined by the absolute value of market returns $\left(\operatorname{ABS}\left(R_{t}\right)\right)$

Panel A shows the estimates of the two models (standard errors in parentheses).

Panel B reports the estimated values of the omitted variable biases (OVB) and the aggregation biases (AB) for the two Basu coefficients $\beta_{0}$ and $\beta_{1}$, according to the calculations presented in Appendix C. For this computation, the estimates of the coefficients of the alternative model are used; the standard deviations and correlations between book-to-market ration and market returns and between the bad news variable and market returns for each subsample are not reported, but they are available from the authors. "Expected" $\beta_{0}$ is calculated as the value of the coefficient $b_{0}$ plus the two biases estimated for $\beta_{0}$. Chi ${ }^{2}$ is a test of the difference between the real estimate of $\beta_{0}$ and the "Expected" $\beta_{0}$. Analogously, "Expected" $\beta_{1}$ is calculated as the value of the difference between the coefficients $b_{1}$ and $b_{0}$ plus the two biases estimated for $\beta_{1}$. Chi $i^{2}$ is a test of the difference between the real estimate of $\beta_{1}$ and the "Expected" $\beta_{1}$ 
Table 5. Descriptive statistics of the firm-specific estimations of the two models

\begin{tabular}{|c|c|c|c|c|c|c|c|c|}
\hline & $\beta_{0}$ & $\beta_{1}$ & $\beta_{0}+\beta_{1}$ & $R^{2}$ & $b_{0}$ & $b_{1}-b_{0}$ & $b_{1}$ & $R^{2}$ \\
\hline Mean & 0.0341 & 0.1388 & 0.1730 & 0.1929 & 0.0683 & 0.0568 & 0.1251 & 0.4154 \\
\hline S.D. & 0.2850 & 0.5994 & 0.5275 & 0.2897 & 0.1220 & 0.2314 & 0.2393 & 0.3050 \\
\hline p5 & -0.2190 & -0.5046 & -0.3858 & -0.2514 & -0.0775 & -0.2092 & -0.1141 & -0.0839 \\
\hline$p 25$ & -0.0081 & -0.0769 & -0.0216 & 0.0018 & 0.0119 & -0.0407 & 0.0115 & 0.1898 \\
\hline p50 & 0.0388 & 0.0536 & 0.0926 & 0.1617 & 0.0502 & 0.0198 & 0.0692 & 0.4238 \\
\hline p75 & 0.0964 & 0.2646 & 0.2760 & 0.3723 & 0.1079 & 0.1151 & 0.1875 & 0.6584 \\
\hline p95 & 0.2572 & 1.1053 & 1.0402 & 0.7223 & 0.2679 & 0.4482 & 0.5631 & 0.8860 \\
\hline Positive & 3041 & 2590 & 3010 & & 3442 & 2514 & 3374 & \\
\hline$p<.10$ & 1041 & 549 & 698 & & 1849 & 662 & 1291 & \\
\hline$p<.05$ & 782 & 351 & 481 & & 1468 & 473 & 931 & \\
\hline Negative & 1203 & 1654 & 1234 & & 802 & 1730 & 870 & \\
\hline$p<.10$ & 263 & 157 & 71 & & 171 & 269 & 71 & \\
\hline$p<.05$ & 199 & 77 & 26 & & 115 & 168 & 38 & \\
\hline
\end{tabular}

This table reports the descriptive statistics of the firm-specific estimations of the two following models: Basu model:

$$
A N I_{t}=\alpha_{0}+\alpha_{1} \cdot d_{t}+\beta_{0} \cdot R_{t}+\beta_{1} \cdot d_{t} \cdot R_{t}+\varepsilon_{t}
$$

Alternative model:

$$
A N I_{t}=a_{0}+a_{1} \cdot\left(1-B T M_{t-1}\right)+b_{0} \cdot R_{t}^{+}+b_{1} \cdot R_{t}^{-}+\varepsilon_{t}
$$

Where $A N I_{t}$ is the accounting net income of the year $t$ divided by the market value of equity at the beginning of the year $t ; R_{t}$ is the market rate of return of the year $t ; d_{t}$ is a dummy variable that takes the value of 1 if $R_{t}$ is negative and 0 otherwise; $B T M_{t-1}$ is the book-to-market ratio at the beginning of period $t$; $R_{t}^{+}$is the sum of all the monthly positive variations in the market value of equity during the period $t$ divided by the market value of equity at the beginning of the year $t$; and $R_{t}^{-}$is the sum of all the monthly negative variations in the market value of equity during the year $t$ divided by the market value of equity at the beginning of the year $t$.

Mean indicates the average of the coefficient; S.D. reports the standard deviation; $P \#$ indicates the percentile of the indicated order; row Positive (Negative) indicate the number of observations for which the value of the coefficient is higher (lower) than zero; $p<\#$ indicates the number of companies for which the obtained coefficient is significant at the indicated level. 


\section{References}

Ball, R., S. Kothari, et al. (2009). "Econometrics of the Basu Asymmetric Timeliness Coefficient and Accounting Conservatism". Working Paper, University of Chicago.

Basu, S. (1997). "The Conservatism Principle and Asymmetric Timeliness of Earnings." Journal of Accounting and Economics, 24, pp. 3-37.

Chung, H. H. and J. P. Wynn (2008). "Managerial legal liability coverage and earnings conservatism." Journal of Accounting and Economics, 46(1), pp. 135-153.

Dietrich, J. R., K. A. Muller, et al. (2007). "Asymmetric timeliness tests of accounting conservatism." Review of Accounting Studies, 12(1), pp. 95-124.

Fama, E. and K. French (1992). "The cross-section of expected stock returns." Journal of Finance, 47, pp. 427-465.

García-Lara, J. M., B. García-Osma, et al. (2009). "The Economic Determinants of Conditional Conservatism." Journal of Business Finance and Accounting, 36(3), pp. 336-372.

Givoly, D., C. Hayn, et al. (2007). "Measuring reporting conservatism." The Accounting Review, 82(1), pp. 65-106.

Khan, M. and R. L. Watts (2009). "Estimation and empirical properties of a firm-year measure of accounting conservatism." Journal of Accounting and Economics, 48(2-3), pp. 132-150.

Kung, F.-H., C.-L. Cheng, et al. (2010). "The effects of corporate ownership structure on earnings conservatism: evidence from China." Asian Journal of Finance \& Accounting, 2(1), pp. 47-67.

Lewellen, J. (1999). "The time-series relations among expected return, risk, and bookto-market." Journal of Financial Economics, 54, pp. 5-43.

Patatoukas, P. N. and J. K. Thomas (2009). "Evidence of Conditional Conservatism: Fact or Artifact? ". Working Paper, Yale University.

Patatoukas, P. N. and J. K. Thomas (2011). "More Evidence of Bias in the Differential Timeliness Measure of Conditional Conservatism." The Accounting Review, Forthcoming.

Petersen, M. A. (2009). "Estimating Standard Errors in Finance Panel Data Sets: Comparing Approaches." Review of Financial Studies, 22, pp. 435-480.

Pontiff, J. and L. D. Schall (1998). "Book-to-market ratios as predictors of market returns." Journal of Financial Economics, 49, pp. 141-160.

Qiang, X. (2007). "The effects of contracting, litigation, regulation and tax costs on conditional and unconditional conservatism: cross-sectional evidence at the firm level." The Accounting Review, 82(3), pp. 759-796.

Ryan, S. (2006). "Identifying Conditional Conservatism." European Accounting Review, 15(4), pp. 511-525.

Zhang, J. (2008). "The contracting benefits of accounting conservatism to lenders and borrowers." Journal of Accounting and Economics, 45(1), pp. 27-54. 